\title{
GIS Based Novel Hybrid Computational Intelligence Models for Mapping Landslide Susceptibility: A Case Study at Da Lat City, Vietnam
}

\author{
Viet-Tien Nguyen ${ }^{1,2}$, Trong Hien Tran ${ }^{1}$, Ngoc Anh Ha ${ }^{1}$, Van Liem Ngo ${ }^{3}{ }^{(D)}$, \\ Al-Ansari Nadhir ${ }^{4, *}$, Van Phong Tran ${ }^{1}{ }^{(0}$, Huu Duy Nguyen ${ }^{3}$, Malek M. A. ${ }^{5}$, Ata Amini ${ }^{6}{ }^{(}$, \\ Indra Prakash ${ }^{7}$, Lanh Si Ho ${ }^{8, *}$ and Binh Thai Pham ${ }^{9, *(\mathbb{D}}$ \\ 1 Institute of Geological Sciences, Vietnam Academy of Science and Technology, 84 Chua Lang, Dong da, \\ Hanoi 100000, Vietnam; nvtien@igsvn.vast.vn (V.-T.N.); trantronghien@igsvn.vast.vn (T.H.T.); \\ hangocanh@igsvn.vast.vn (N.A.H.); tvphong@igsvn.vast.vn (V.P.T.) \\ 2 Graduate University of Science and Technology, Vietnam Academy of Science and Technology, \\ 18 Hoang Quoc Viet, Cau Giay, Hanoi 100000, Vietnam \\ 3 Faculty of Geography, VNU University of Science, Vietnam National University, Hanoi, 334 Nguyen Trai, \\ Thanh Xuan, Hanoi 100000, Vietnam; liemnv@hus.edu.vn (V.L.N.); nguyenhuuduy@hus.edu.vn (H.D.N.) \\ 4 Department of Civil, Environmental and Natural Resources Engineering, Lulea University of Technology, \\ 97187 Lulea, Sweden \\ 5 Institute of Sustainable Energy, University Tenaga Nasional, Selangor 43000, Malaysia; \\ marlinda@uniten.edu.my \\ 6 Kurdistan Agricultural and Natural Resources Research and Education Center, AREEO, \\ Sanandaj 66177-15175, Iran; a.amini@areeo.ac.ir \\ 7 Department of Science and Technology, Bhaskarcharya Institute for Space Applications and \\ Geo-Informatics (BISAG), Government of Gujarat, Gandhinagar 382007, India; bisagsp16@gujarat.gov.in \\ 8 Institute of Research and Development, Duy Tan University, Da Nang 550000, Vietnam \\ 9 University of Transport Technology, Hanoi 100000, Vietnam \\ * Corresponding authors: nadhir.alansari@ltu.se (A.-A.N.); hosilanh@duytan.edu.vn (L.S.H.); \\ binhpt@utt.edu.vn (B.-T.P.)
}

Received: 11 October 2019; Accepted: 10 December 2019; Published: 12 December 2019

\begin{abstract}
Landslides affect properties and the lives of a large number of people in many hilly parts of Vietnam and in the world. Damages caused by landslides can be reduced by understanding distribution, nature, mechanisms and causes of landslides with the help of model studies for better planning and risk management of the area. Development of landslide susceptibility maps is one of the main steps in landslide management. In this study, the main objective is to develop GIS based hybrid computational intelligence models to generate landslide susceptibility maps of the Da Lat province, which is one of the landslide prone regions of Vietnam. Novel hybrid models of alternating decision trees (ADT) with various ensemble methods, namely bagging, dagging, MultiBoostAB, and RealAdaBoost, were developed namely B-ADT, D-ADT, MBAB-ADT, RAB-ADT, respectively. Data of 72 past landslide events was used in conjunction with 11 landslide conditioning factors (curvature, distance from geological boundaries, elevation, land use, Normalized Difference Vegetation Index (NDVI), relief amplitude, stream density, slope, lithology, weathering crust and soil) in the development and validation of the models. Area under the receiver operating characteristic (ROC) curve (AUC), and several statistical measures were applied to validate these models. Results indicated that performance of all the models was good (AUC value greater than 0.8) but B-ADT model performed the best $(A U C=0.856)$. Landslide susceptibility maps generated using the proposed models would be helpful to decision makers in the risk management for land use planning and infrastructure development.
\end{abstract}


Keywords: landslides; alternating decision trees; bagging; dagging; MultiBoostAB; RealAdaBoost; hybrid models

\section{Introduction}

Landslides are one of the most devastating natural disasters all over the world, especially in mountain regions affecting the economy and lives of the people [1,2]. In recent years, many studies were conducted to assess the risk of landslides, and to develop susceptibility maps with the objectives of reducing damages and fatalities [1,3]. According to World Bank reports, approximately 3.7 million $\mathrm{km}^{2}$ of surface area worldwide is vulnerable to landslides, whereby $820,000 \mathrm{~km}^{2}$ is in high-risk zones. Even developed countries, like Italy, Switzerland, Austria, and France have lost about 1 to 5 billion USD, and the United States about 3.5 billion USD [4] every year from damages due to landslides. Landslides also cause changes in the morphology of the area, including river courses [5]. Vietnam is located in the tropical monsoon region, which is mostly affected by natural disasters like flash floods or landslides [6,7]. About $22 \%$ of landslides occur in hilly areas of Vietnam, during monsoon period (average rainfall $800 \mathrm{~mm}$ ) from July to September due to a combination of various factors such as topography, geology, and other geo-environmental factors including precipitation [8]. According to reports from the Ministry of Agriculture and Rural Development, $40 \%$ of the area in Vietnam was covered by the forest [9]. However, in recent years, vegetation cover has been reduced due to developmental activities. Anthropogenic activities, forest fires and the effects of climate change have increased natural disasters like landslides in Vietnam.

Current research on landslides can be divided into two groups: Qualitative approach and quantitative approach. The qualitative approach is based on the experiences and knowledge of experts. Analytic hierarchy process (AHP) is one of the best-known models of this approach $[10,11]$. However, with the development of computational power and geographic information system (GIS), nowadays, the quantitative approach — which is better and more objective than the qualitative approach-is more widely used in landslide studies. This approach includes traditional statistical models and machine learning (ML) based models. Traditional statistical methods include frequency ratio (FR) [12,13], evidential belief function (EBF) [14,15], and weights of evidence (WOE) [16,17]. Arabameri et al. [18] applied statistical index model-based landslide susceptibility mapping to reduce errors of experts, corresponding to the subjective re-classification. ML based models include alors que naïve Bayes (AQNB) [19,20], logistic model trees (LMT) [21,22], support vector machines (SVM) [23,24], neuro fuzzy (NF) $[25,26]$, decision tree (DT) $[27,28]$, artificial neural networks (ANN) $[29,30]$, logistic regression (LR) [31,32]. He et al. [33] suggested that ML based models are good for landslide susceptibility mapping.

In recent years, many hybrid ML based models were developed for better landslide susceptibility mapping. The main idea of these hybrid models is to combine the optimization techniques with weak classifiers to improve the accuracy in landslide susceptibility modeling. Bui et al. [34] developed a hybrid model by combining least squares support vector classification (LSSVC) and bat algorithm (BA) to analyze landslide susceptibility in Lang Son province (Vietnam), and concluded that the new hybrid model was better than other benchmark ML based models like ANN and LR. In another study, Chen et al. [35] developed a hybrid ML based model (RF-NBT) which is a combination of rotation forest and naïve Bayes tree classifier to construct the landslide susceptibility map in Langao County, China, and concluded that the proposed RF-NBT model had increased accuracy of prediction compared with other models, namely logistic model tree (LMT), functional tree (FT), and reduced-error pruning tree (REPT) which are benchmark ML based models. In general, the ML based models-especially hybrid models-are considered to be a relatively more efficient method in comparison to the traditional statistical and qualitative methods.

In this study, the main objective is to develop and compare GIS based hybrid computational intelligence models to generate landslide susceptibility maps of the Da Lat province, which is one of 
the most landslide prone areas of Vietnam. For this purpose, four hybrid models, namely B-ADT, D-ADT, MBAB-ADT, RAB-ADT, which are a combination of alternating decision trees (ADT) and ML methods namely bagging, dagging, MultiBoostAB, and RealAdaBoost, respectively, were developed. Performance of these models was validated using area under the receiver operating characteristic (ROC) curve and several statistical measures. Weka software was used to construct and validate the models, whereas ArcGIS application was used to prepare datasets and generate maps.

\section{Description of Study Area}

Da Lat city is located in the northeast area of Lam Dong province in the Central Highlands region of Vietnam $\left(11^{\circ} 56^{\prime} 25^{\prime \prime}\right.$ North and $108^{\circ} 26^{\prime} 13^{\prime \prime}$ East) (Figure 1). Topography of the study area is marked by high mountains, low hills and intervening valleys. The northern and northwestern regions are marked by Lang Biang Mountain. The East and Southeast hilly areas gradually lower into the valley of Da Nhim, whereas the West and Southwest areas gradually lower to the plateau of Di Linh. The average altitude of the area is $1520 \mathrm{~m}$ above mean sea level.

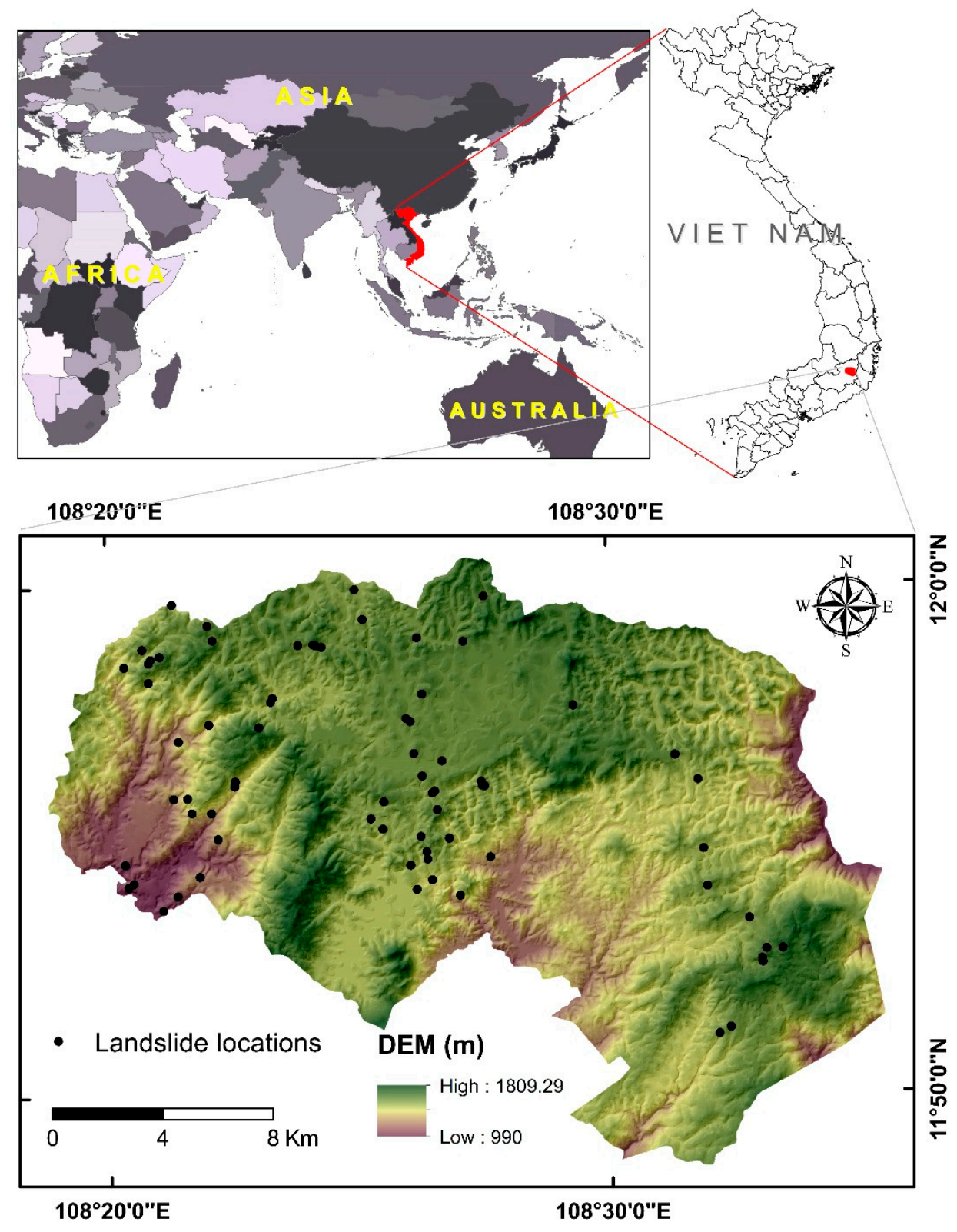

Figure 1. Localization of Da Lat city, Vietnam. 
Climate of the Da Lat region is of subtropical monsoon type, divided into two main seasons: The rainy season (April to October) and the dry season (November to March). Average annual rainfall is about $1800 \mathrm{~mm}$. Precipitation intensity is concentrated during the months of August and September each year.

In the Da Lat city area, there are more than 20 streams with average length of over $4 \mathrm{~km}$. These streams are upstream tributaries of the Dong Nai River. In the river basin, 14 streams originate from an altitude of over $1500 \mathrm{~m}$. Density of the stream networks in the North, East and South of the city areas is about 0.6 to $0.9 \mathrm{~km} / \mathrm{km}^{2}$. The average slope of the river basins is 30-40 degrees. Types of soils present in the area are: Ferralitic soils, soils with yellow-gray humus (Fha), alluvial soils (P), sloping soils (Dt) formed due to alteration, erosion and sedimentation of sedimentary and metamorphic rocks. In recent years, urbanization has reduced the forest and cultivated areas. Forest Fire, global climate change effects and anthropogenic activities are responsible for the reduction of forest areas and degradation of land cover.

\section{Methods and Materials}

\subsection{Methods Used}

\subsubsection{Base Classifier of Alternating Decision Tree (ADT)}

ADT is one of the machine learning algorithms often used in classification problems including landslide prediction [36,37]. ADT works on a principle that through combining weak hypotheses, which are created during the boosting procedure, modeling process would be better interpretable. The main difference in ADT compared with traditional decision tree methods is that it allows each part to be split more than one time [38].

In a classification problem, the rules of a general ADT can be defined as follows: A set of paths in the alternating tree is defined by an instance. As in standard decision trees, when a decision node is reached by a path, it continues with the sub-path (or the child) that corresponds to the result of the decision linked with that node. On the contrary, when a prediction node is reached, the path continues with all of the sub-paths (or children) of that node. Literally, the path splits into a set of paths, and each one corresponds to one of the children belonging to the prediction node, respectively. The "multi-path", associated with that instance, is then defined as the ensemble of all the paths that are reached for a given instance by this manner. All the prediction nodes in each multi-path are then summed up to define a sign which directly relates to the classification of the tree associated with that instance [39]. A detailed description of this method is mathematically represented by Freund and Mason [38].

\subsubsection{Ensemble Techniques}

\subsubsection{Bagging}

Bagging technique comes from a merger of "Bootstrap-Aggregating", where it combines bootstrapping and aggregation to form a unique ensemble model [40]. Considering a sample of a dataset, a base classifier is developed on a base of each of the bootstrapped subsamples, where they were previously pulled out. Once formed, another algorithm is then used to aggregate the base classifiers to form the more powerful predictor [41]. Bagging can improve the performance of the weak classifiers as it is able to decreases the variance of each classifier [42]. In terms of prediction problems, theoretically, it is justified that a bagged model will always have amended precision in comparison with a single predictor [43]. A detailed description of this method is mathematically represented by Breiman [44].

\subsubsection{Dagging}

Dagging is a popular ensemble technique which is often used to construct meta-classifiers [45]. This technique differs from the boosting and bagging methods in several ways. For example, depending 
on the performance of the previously created classifiers, the boosting procedure adaptively modifies the training data set in terms of distribution, while bagging modifies it stochastically and boosts bases on the performance of each classifier as a weight for voting. Dagging creates a number of disjointed and stratified folds out of data and feeds each part of data to a copy of the supplied base learner [45]. The final prediction results are made on a principle of plurality vote, where all the basic classifiers generated have been previously entered into the meta-classifiers [46].

In general, in terms of data without noise processing, the boosting algorithms are rated better, compared to dagging and bagging. Nevertheless, dagging and bagging are evaluated more accurately compared to boosting to treat the problems with noisy data [45]. A detailed description of this method is mathematically represented by Ting and Witten [45].

\subsubsection{MultiBoostAB}

MultiboostAB technique is also a classification ensemble algorithm constructed by many classifiers, generated via the classifying-learning process [47]. Misclassification could be considerably reduced thanks to the variety of classifiers. Basically, MultiboostAB is an integration of Adabosst and wagging which are universal and typical ensemble methods for classification problems. The main advantage of MultiboostAB lies in the reality that the reduction of deviation and variance is related to wagging and Adaboost [42]. The different classifiers are established by applying the training data in the MultiboostAB algorithm, and then the classifier's weights are tuned to improve the precision of the classification process [47]. A detailed description of this method is mathematically represented by Webb [47].

\subsubsection{RealAdaBoost}

RealAdaBoost proposed by Schapire R.E. and Singer Y. [48] is known as a generalization of the Adaboost algorithm. AdaBoost algorithm is the most representative boosting method, and is a combination of adaptive and boosting [49], based on an iterative scheme, in which the variance feeble learners are built on a similar set of the weighted training dataset. The prediction product of the feeble learners is the integration into a sum of all weights to construct a more accurate classifier. It has been noticed that it is crucial for AdaBoost to maintain a weight division until the training dataset is accomplished. During this process, the algorithm is centralized on the more difficult cases to classify, by gradually increasing their weights. When the active learner is found in the final, AdaBoost increases the weights of feeble learners with higher classification accuracy. A detailed description of this method is mathematically represented by Schapire R.E. and Singer Y. [48].

\subsubsection{Validation Criteria}

For validation of the ML based models, many criteria could be applied for the validation/ assessment of the performance of the models. In this study, prediction accuracy of the proposed models was assessed by the positive predictive value (PPV), negative predictive value (NPV), accuracy (ACC), specificity (SPF), sensitivity (SST), kappa (k), Root Mean Square Error (RMSE), area under the ROC curve (AUC) [50-52]. More specifically, PPV and NPV are the probability of pixels associated with correct classification of landslide and non-landslide, respectively [53]. SST, SPF are the proportions of landslide pixels associated with the correct classification of landslide and non-landslide, respectively. ACC is the proportion of true negative and true positive classification results, which means it is the proportion of landslide and non-landslide pixels classified correctly [54]. These validation criteria were determined by using the definitions of true positive (TP), false positive (FP), true negative (TN) and false negative (FN) as below [55]:

$$
\begin{gathered}
P P V=\frac{T P}{T P+F P} \\
N P V=\frac{T N}{T N+F N}
\end{gathered}
$$




$$
\begin{gathered}
S S T=\frac{T P}{T P+F N} \\
S P F=\frac{T N}{F P+T N} \\
A C C=\frac{T P+T N}{T P+T N+F P+F N}
\end{gathered}
$$

Kappa ( $\mathrm{k}$ ) is employed to assess accuracy in the landslide modeling process [54]. Kappa changes from-1 (non-reliable) to 1 (reliable) [56]. It can be calculated using the following equation:

$$
k=\frac{P_{p}-P_{\text {exp }}}{1-P_{\text {exp }}}
$$

where $P_{p}$ is accuracy and $P_{\exp }$ are the expected agreements.

RMSE is often used to evaluate the differences between the predicted and target values [57-62], it can be calculated using the following equation:

$$
\text { RMSE }=\sqrt{\frac{1}{m} \sum_{i=1}^{m}\left(e_{i}-\bar{e}_{i}\right)^{2}}
$$

where $m$ is the number of samples, $e_{i}$ and $\bar{e}_{i}$ are the output and the target values of the $i$-th samples, respectively. RMSE has the same error metric units as the data, and smaller RMSE values indicate better performance of a model [60,63-68].

AUC is defined as the area under the ROC curve which is constructed using two statistical values: "Sensitivity" and "100-specificity" $[52,69,70]$. It is a very common, standard criterion and fundamental tool to evaluate the performance of an ML based model [71,72]. An ROC curve closer to the top-left corner indicates a better model $[73,74]$. The closer the curve comes to the 45-degree diagonal, the less accurate $[75,76]$. AUC is a measure of the accuracy of the models: 1 is optimal and 0.5 is poor $[50,51]$.

\subsection{Data Used}

\subsubsection{Landslide Inventory}

Generation of the landslide maps using machine learning methods requires a knowledge of the historical landslide events [74,77]. Thus, the landslide inventory map is vital for determining the spatial links of historic earth slips with factors of geomorphological, hydrological, climatic factors, and anthropogenic activities [78,79]. In this study, an inventory map with 72 landslide locations was developed from satellite Google Earth images in conjunction with the field data of the national project of Vietnam Academy of Science and Technology, namely "a study on scientific basis to build an automatic sliding warning monitoring system in some key urban areas in Central Highlands" (http://www.vast.ac.vn/en/). Slides in the area were mainly of two types: Rock and Debris slides. Most of the slides were observed along road cuttings, during rainy seasons where ground mass/rock mass was vulnerable to sliding (Figure 2). 


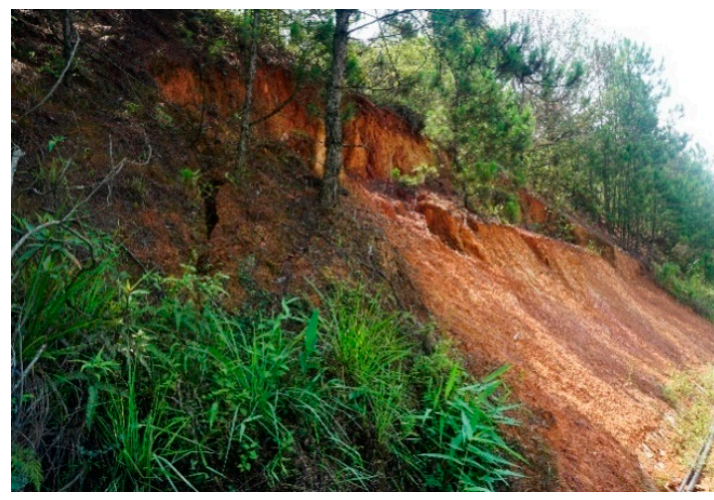

(a)

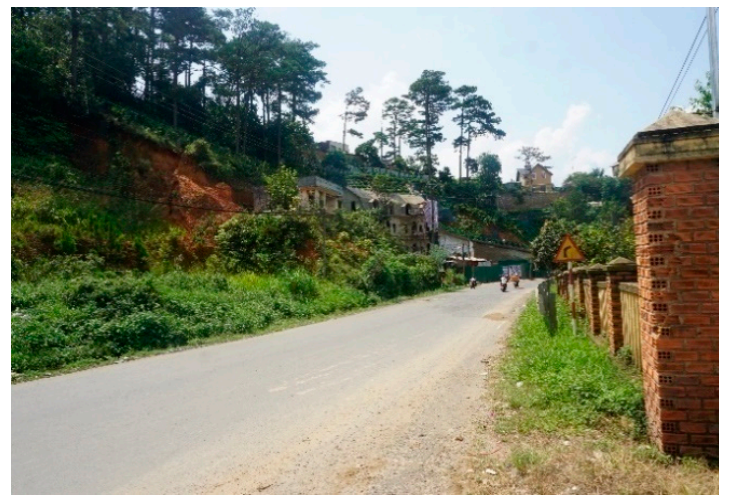

(c)

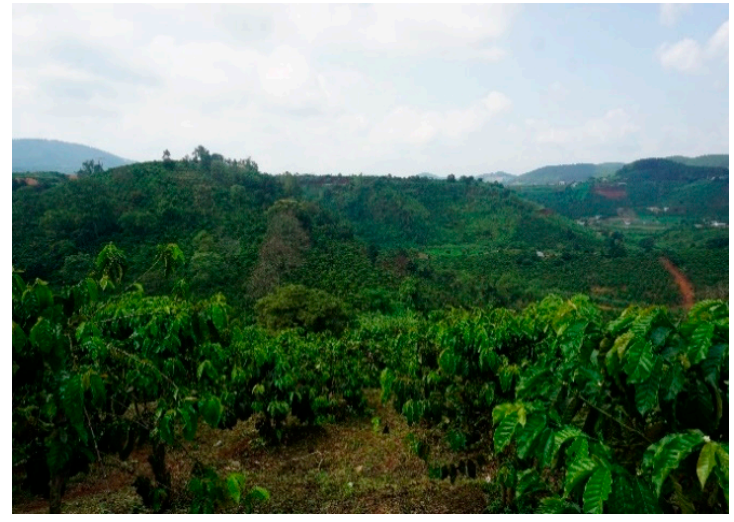

(b)

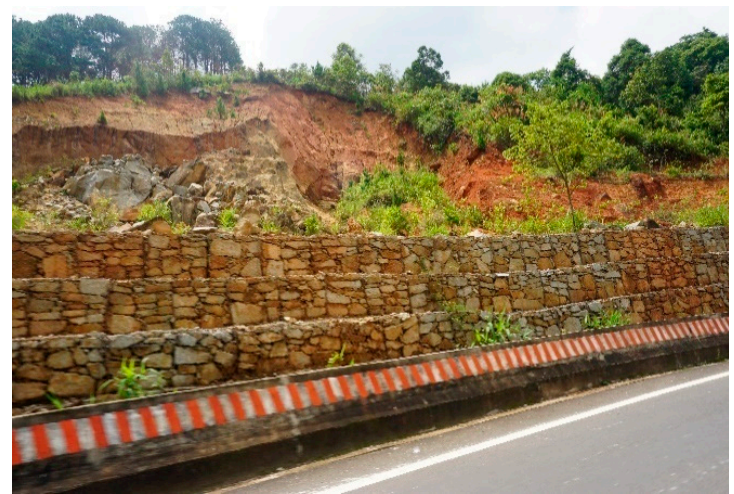

(d)

Figure 2. Landslide photos in the study area: $(\mathbf{a}, \mathbf{b})$ landslides on hilly areas; $(\mathbf{c}, \mathbf{d})$ landslides along the roads (taken by Vietnam Academy of Science and Technology—http://www.vast.ac.vn/en/).

\subsubsection{Landslide Influencing Parameters}

Selection of the conditioning factors is essential and a mandatory step in landslide susceptibility assessment [37]. These factors can be divided into four groups: Physical geographic factors, hydrological factors, climate factors, and anthropogenic activity related factors [80]. In this study, 11 conditioning factors were selected for the landslide susceptibility modeling, namely curvature, distance from geological boundaries, elevation, land use, Normalized Difference Vegetation Index (NDVI), relief amplitude, stream density, slope, lithology, weathering crust and soil. These factors were selected based on the types of landslides and local topography and geo-environmental characteristics of the study area. Geology, soil and weathering data was obtained from the Vietnam Academy of Science and Technology, Vietnam (http://www.vast.ac.vn/en/).

Curvature is a geomorphological factor which controls the flow of water on the surface and influences the runoff and storage of water [46,81]. A curvature map was generated from a digital elevation model (DEM) with $20 \mathrm{~m}$ resolution constructed from the topography map of the area available on a scale of $1 / 50,000$, and classified into three classes: Concave $(<-0.05)$, flat $(-0.05-0.05)$ and convex $(>0.05)$ (Figure 3a). Distances from geological boundaries and geological structures (joints, fractures and faults) are important factors as they form sliding planes and control sliding. In this study, six classes of distances from geological boundaries were constructed: 0-100, 100-200, 200-300, 300-400, 400-500, and $>500 \mathrm{~m}$ (Figure $3 \mathrm{~b}$ ). Elevation is an important factor in the landslide analysis [82,83] as it affects rainfall, weathering and soil formation. An elevation map of the study area was generated from DEM and classified into 9 classes based on the natural break classification method: 990-1131, 1131-1221, 1221-1301, 1301-1366, 1366-1420, 1420-1471, 1471-1523, 1523-1584, 1584-1809 m (Figure 3c). 


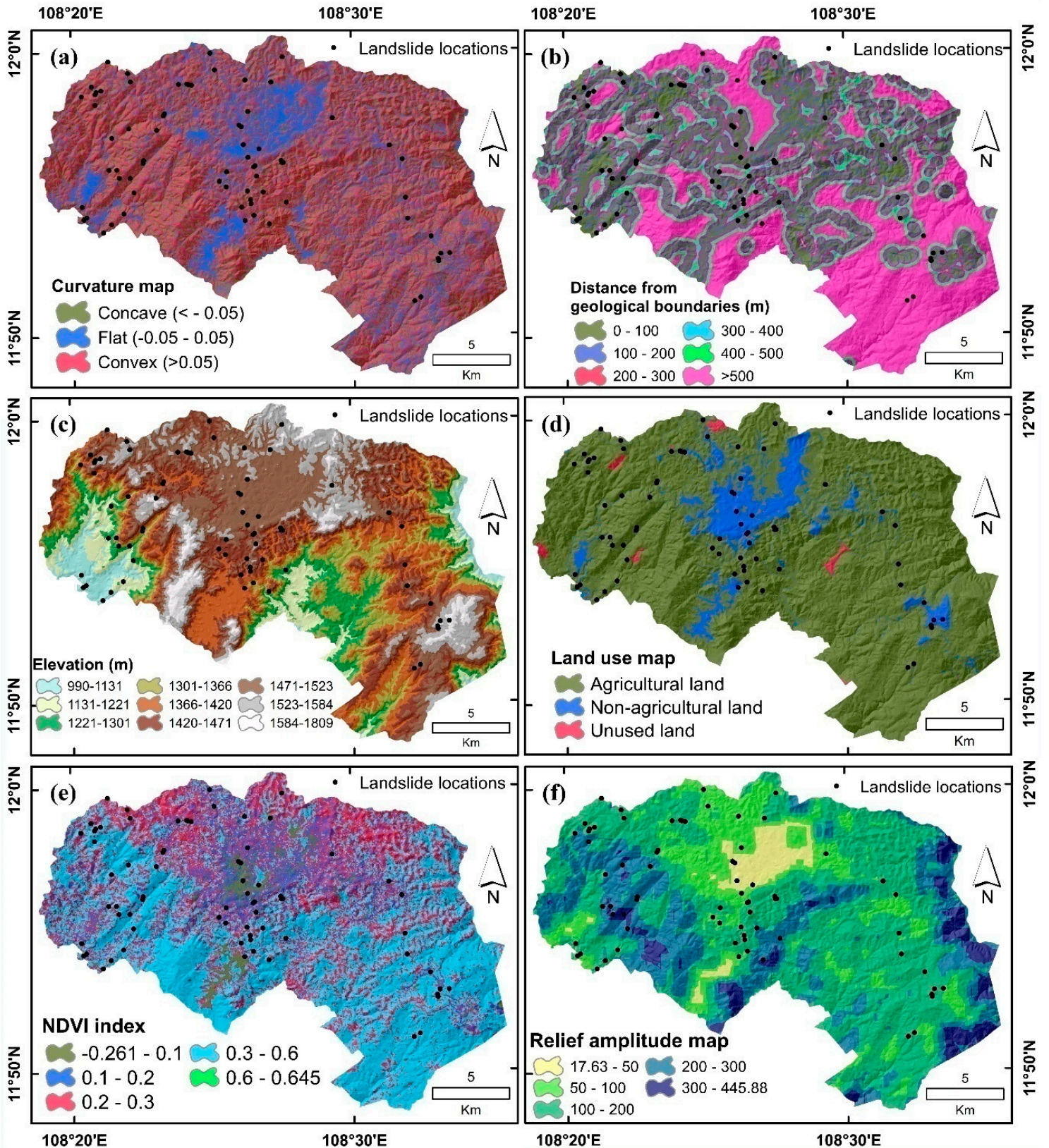

Figure 3. Cont. 

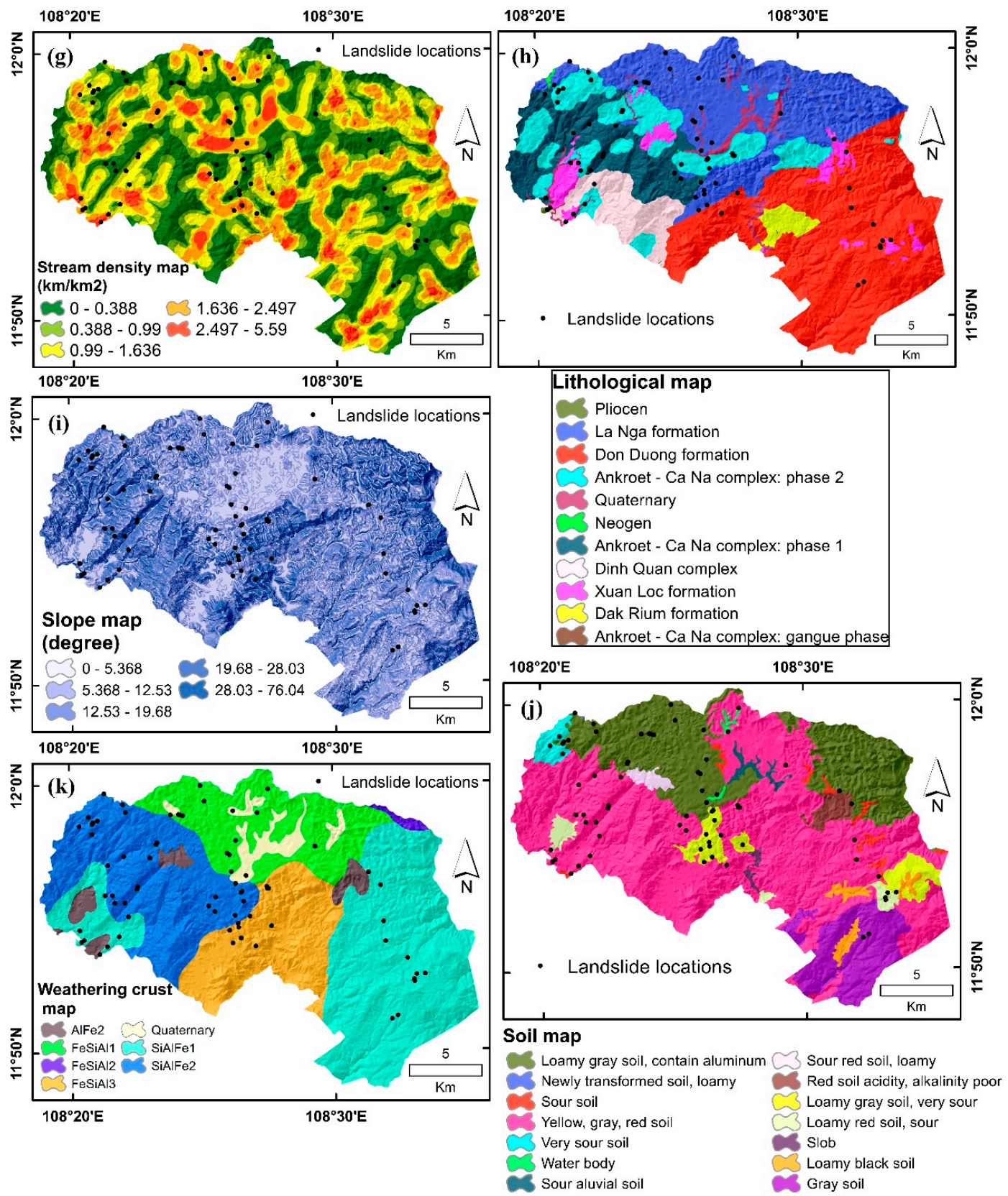

Figure 3. Landslide conditioning factors maps: (a) Curvature, (b) distance to geological boundaries, (c) elevation, (d) land use, (e) NDVI, (f) relief amplitude, (g) stream density, (h) lithology, (i) slope, (j) soil, and (k) weathering crust.

Land use is one of the critical factors influencing landslide by affecting infiltration, runoff and soil erosion in conjunction with geo-environmental factors [46,72]. In the study, area land use was classified into 3 classes: Agricultural land, non-agricultural land, and barren land (Figure 3d). Landslides are predominant in areas of barren land, on the contrary forest land is less vulnerable to landslides [84]. An NDVI map of land use patterns was created with 5 classes: $-0.264-0.1,0.1-0.2,0.2-0.3,0.3-0.6$, $0.6-0.645$ (Figure 3e). There is direct correlation between relief amplitude and slope, with the occurrence and distribution of landslides [85]. Relief amplitude map was constructed using the focal statistic module in the ArcGIS application, and classified into 5 classes: 17.63-50, 50-100, 100-200, 200-300, $300-445.88 \mathrm{~m}$ (Figure 3f). Curvature affects runoff. Generally, runoff will be more in highly dense areas of streams [86]. The stream density map was extracted from DEM and classified into 5 classes based on 
the natural break classification method: 0-0.388, 0.388-0.99, 0.99-1.636, 1.636-2.497, 2.497-5.59 km/km² (Figure 3g).

The lithology map represents physical characteristics of rocks and soils including color, texture, grain size, and composition [87]. In the study area, 11 types of lithology are present: Pliocen, La Nga formation, Don Duong formation, Ankroet-Ca Na complex: Phase 2, Quaternary, Neogen, Ankroet-Ca Na complex: Phase 1, Din Quan complex, Xuan Loc formation, DakRium formation, Ankroet-Ca Na complex: Gangue phase (Figure 3h). Slope is an important factor for analyzing slope stability, as probability of the occurrence of the landslide depends on the proportionality of the slope $[88,89]$. The slope map was divided into 5 classes: $0-5.368,5.368-12.53,12.53-19.68,19.68-28.03,28.03-76.04$, based on the natural break classification method (Figure 3i).

Physical characteristics of the soil affect the infiltration and run-off capacity, and thus influences the landslide susceptibility [79]. In the study area, several types of soils were present, namely loamy gray soil, soil containing aluminum, newly transformed soil, loamy, sour soil, yellow, gray, red soil, very sour soil, sour red soil, loamy, red soil (acid), alkalinity poor soil, slob, loamy back soil, and gray soil (Figure 3j). Like soil, weathered rocks also influence infiltration and runoff of the area. Kvzoglu classified weathering crusts based on the changes in texture, mineral composition, and structure of lithology units [90]. Four types of weathering crusts were present in the area namely AIFE2, FesiAI1, FesiAI2, FesiAI3, Quaternary, SiAIFe1, SiAIFe2 (Figure 3k).

\subsection{Methodological Flow Chart for Landslide Susceptibility Assessment}

Methodology of the present study is described in four main steps: 1. Preparation of data; 2. building landslide susceptibility models; 3 . validation of models; and 4. preparation of landslide susceptibility maps.

\subsubsection{Preparation of Datasets}

Datasets include training, and testing was prepared in this step. First of all, landslide inventory was divided randomly into two parts with the ratio of $70 / 30$. Out of these, $70 \%$ of landslide inventory was used to sample with the conditioning factors for generating the training dataset, whereas $30 \%$ remaining landslide inventory was used to sample with the conditioning factors for creating a testing dataset. The training dataset was used to build the models, whereas the testing dataset was used to validate the models.

\subsubsection{Building Landslide Susceptibility Models}

In this step, four hybrid models, namely B-ADT, D-ADT, MBAB-ADT, RAB-ADT were constructed, and the ADT model was applied using the training dataset. These four hybrid models are a combination of ADT classifier with various ensemble techniques such as bagging, dagging, MultiBoostAB, and RealAdaBoost. In these hybrid models, ensemble techniques were used to optimize training dataset for inputting into ADT classifier. To build these models, the inner parameters of each model was optimized and used. More specifically, ADT was trained and built with the number of boosting interactions being 10, and the number of seed being 1 . Bagging was trained with a bag-size percent of 100,1 as the number of execution slots, 10 as the number of iterations, and 1 as the number of seed. Dagging was trained with a batch size of 100, 10 as the number of folds, and 1 as the number of seed. MultiBoostAB was trained with batch size of 100, 10 as the number of iterations, 3 as the number of seed, and a weight threshold of 100. RealAdaBoost was trained with a batch size of 100, 3 as the number of iterations, 1 as the number of seed, a shrinkage of 1 , and a weight threshold of 100 . Values of these parameters were optimized using the trial-error process.

\subsubsection{Model Validation}

In this step, validation of the landslide susceptibility models was done using statistical measures such as PPV, NPV, SST, SPE, ACC, RMSE, kappa, and AUC on both training and testing datasets. 
Validation of the models on the training dataset shows the degree of good-fitness of the models with data used, whereas validation of the models on the testing dataset shows the predictive capability of the models.

\subsubsection{Preparation of Landslide Susceptibility Maps}

Preparation of landslide susceptibility maps was done using studied models. It was carried out in two main steps; (i) generating landslide susceptibility indexes (LSI) using the results of training models, and (ii) classifying LSI using a standard classification method, namely geometric interval integrated in ArcGIS application. In the present study, the maps were classified into five classes, namely very low, low, moderate, high and very high landslide susceptibility (Figure 4).

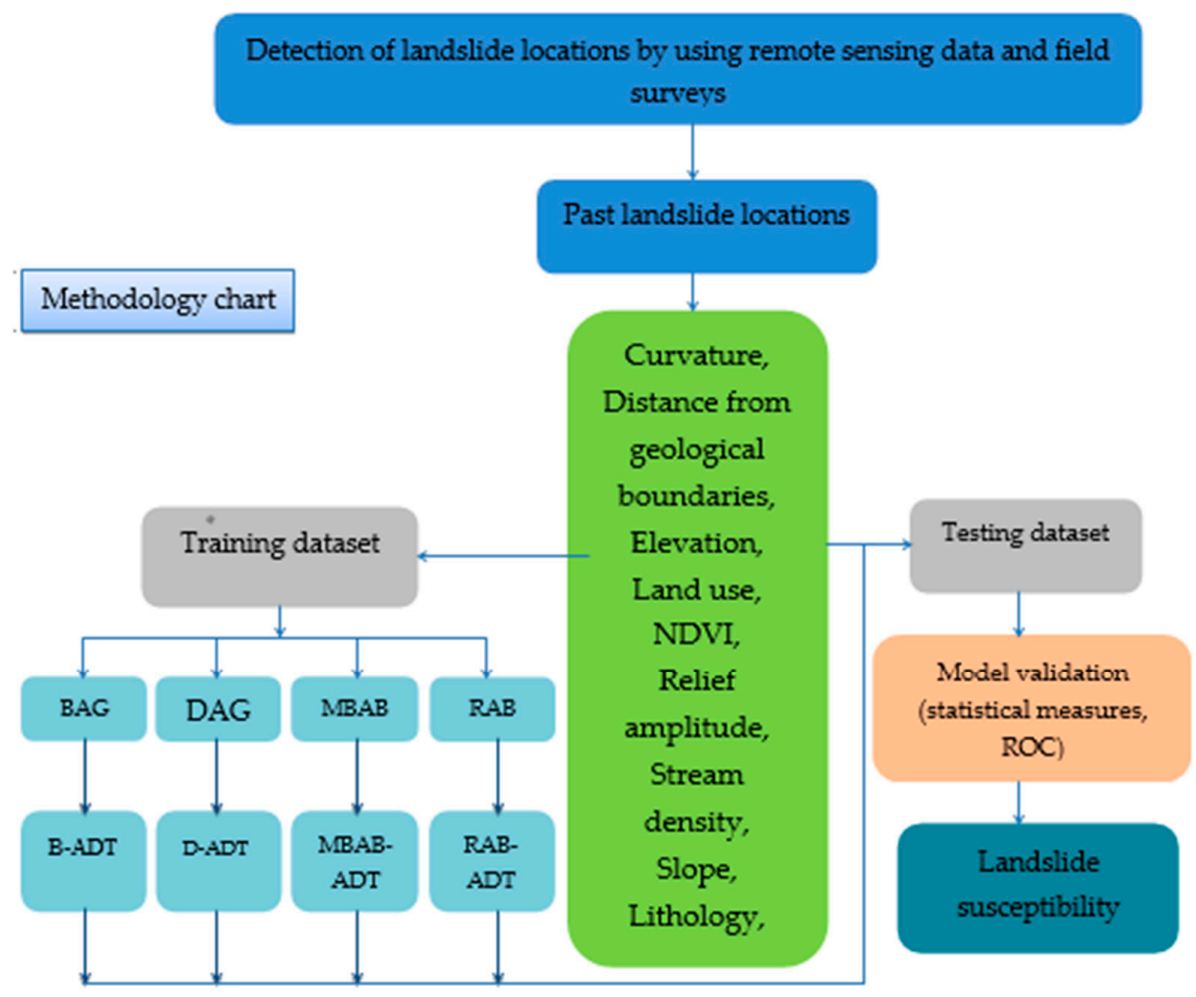

Figure 4. Methodology flow chart of this study (Note; BAG: bagging, DAG: dagging, MBAB: MultiBoostAB, and RAB: RealAdaBoost).

\section{Results and Discussion}

\subsection{Analysis of Spatial Relationship between Past Landslides and the Conditioning Factors}

Landslide influencing factors such as curvature, distance from geological boundaries, elevation, land use, NDVI, relief amplitude, stream density, slope, lithology, weathering crust and soil were used to analyze the spatial relationship with past landslide occurrence using the frequency ratio (FR) method which is a ratio between percentage of landslide pixels and percentage of all pixels on each class of factor map [91] for better generation of the datasets for modeling (Figure 5). FR analysis on the weathering crust indicated that the highest frequency of landslide occurs at the Quaternary $(\mathrm{FR}=1.234)$, and zero on AlFe2 ( $\mathrm{FR}=0)$. In the soil, the highest frequency is on the very sour soil $(F R=4.359)$ and zero value on slob soil $(F R=0)$. In general, the slopes are directly related with the occurrence of landslides. FR analysis shows that the most susceptible slope is 19.68-28.03 (FR = 1.605), followed by 12.53-19.68 ( $\mathrm{FR}=1.237)$, and 28.03-76.04 ( $\mathrm{FR}=0.5295)$, respectively. River density in class: $0-0.388$ sq. $\mathrm{km}$ is more affected by the landslide $(\mathrm{FR}=1.271)$, than the area of river density $1.636-2.497$ sq.km $(\mathrm{FR}=1.153)$. More landslides occur on the relief amplitude of $17.63-50(\mathrm{FR}=1.341)$. 
The area having NDVI $(-0.262-0.1)(\mathrm{FR}=1.87)$ is more susceptible than the area having NDVI 0.2-0.3 $(F R=1.499)$. Geological formation of the Pliocene formation is the most susceptible to landslides $(F R=31.46)$. On the contrary, landslides have not been observed on the DakRium formation and Neogen formation ( $F R=0$ ). Non-agricultural land is affected most by the landslides (FR $=2.511$ ). The area of barren land $(F R=0)$ is very small, only in isolated patches. Most landslides occur $(F R=1.536)$ in the elevation range of $990-1131 \mathrm{~m}$, which is middle range, as at higher elevations geo-environmental conditions do not favor landslides. Buffer zones of geological boundary/features up to $400 \mathrm{~m}$ distance are more susceptible to landslides ( $F R=1.695$ to 1.741). FR analysis indicates that landslides occur more in the convex area $(F R=1.069)$ than concave area $(F R=0.8779)$, as convex topography favors landslide occurrences (Figure 5).

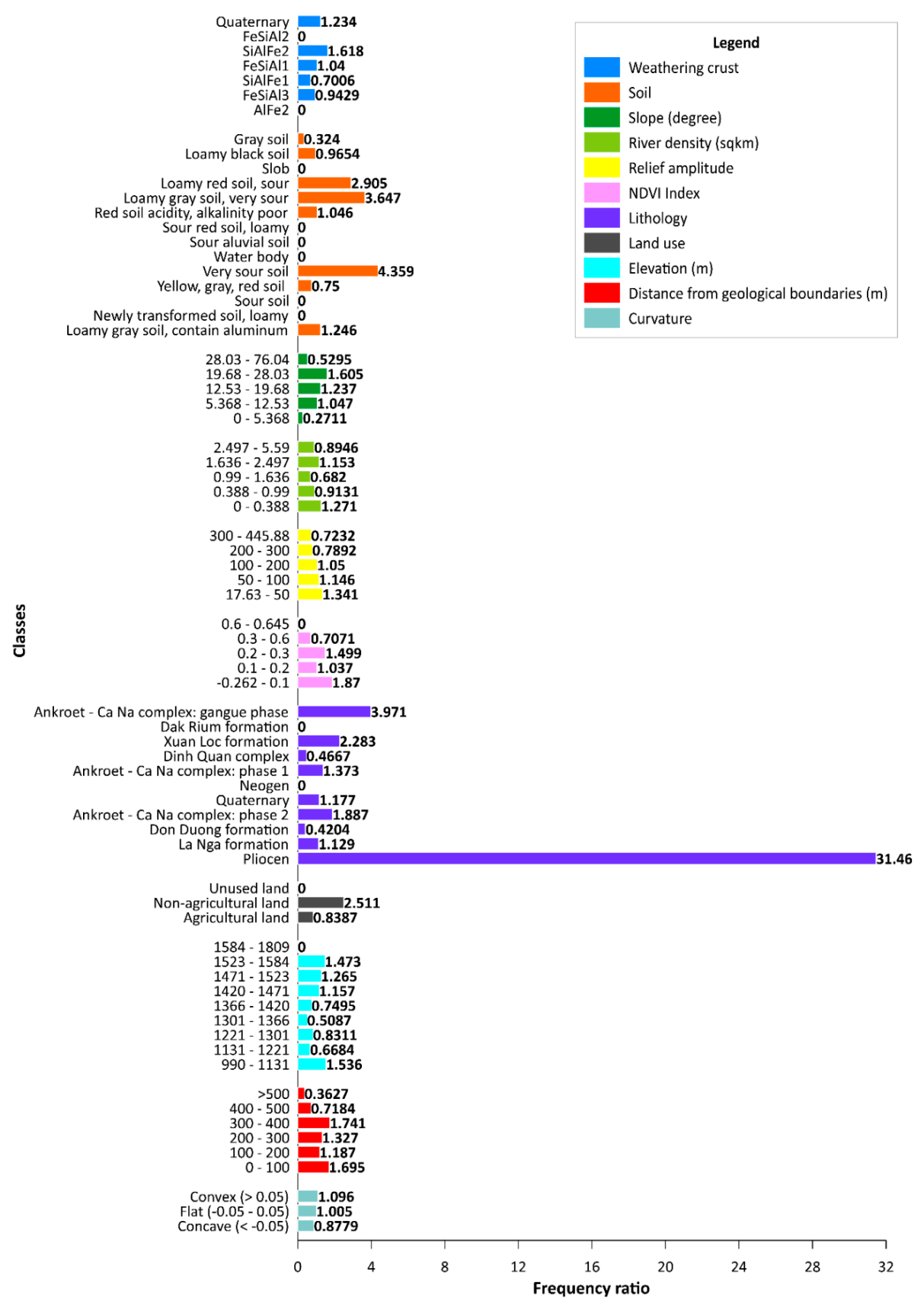

Figure 5. Frequency ratio (FR) of factor maps. 


\subsection{Model Validation and Comparison}

Performance of models was evaluated and validated using training and testing datasets by applying various statistical criteria. The model evaluation in the training phase is presented in Table 1 and Figure 6. Results show that performance of hybrid model RAB-ADT was the best (PPV $=90 \%)$ in terms of PPV, followed by D-ADT (88\%), B-ADT (78\%), MBAB-ADT (76\%), and ADT (70\%) models, respectively. In the case of the NPV, the D-ADT $(\mathrm{NPV}=96 \%)$ model was superior to MBAB-ADT $(94 \%)$, ADT (92\%), RAB-ADT (90\%), and B-ADT (86\%), respectively. The highest SST was for the D-ADT model which correctly classified $95.65 \%$ as landslides, followed by MBAB-ADT $(92.68 \%)$ and RAB-ADT (90\%), ADT (89.74\%), and B-ADT (84.87\%), respectively. The RAB-ADT model also had the highest SPF: 90\%, followed by D-ADT (88.89\%), MBAB-ADT (79.66\%), B-ADT (79.63\%), and ADT (75.41\%), respectively. In terms of ACC, the D-ADT value was $92 \%$, which is superior to RAB-ADT (90\%), MBAB-ADT (85\%), B-ADT (82\%), and ADT (81\%). In terms of kappa index, the D-ADT model performed the best (0.84), demonstrating a substantial to almost perfect agreement between prediction and observation, followed by RAB-ADT (0.8), MBAB-ADT (0.7), B-ADT (0.64), and ADT (0.62), respectively. In terms of RMSE, D-ADT had the lowest value (0.396), followed by ADT (0.378), B-ADT (0.3735), MBAB-ADT (0.364), and RAB-ADT (0.2769), respectively.

Table 1. Validation of the models using training dataset.

\begin{tabular}{ccccccc}
\hline No & Criteria & ADT & B-ADT & D-ADT & MBAB-ADT & RAB-ADT \\
\hline 1 & TP & 35 & 39 & 44 & 38 & 45 \\
2 & TN & 46 & 43 & 48 & 47 & 45 \\
3 & FP & 15 & 11 & 6 & 12 & 5 \\
4 & FN & 4 & 7 & 2 & 3 & 5 \\
5 & PPV (\%) & 70.00 & 78.00 & 88.00 & 76.00 & 90.00 \\
6 & NPV (\%) & 92.00 & 86.00 & 96.00 & 94.00 & 90.00 \\
7 & SST (\%) & 89.74 & 84.78 & 95.65 & 92.68 & 90.00 \\
8 & SPF (\%) & 75.41 & 79.63 & 88.89 & 79.66 & 90.00 \\
9 & ACC (\%) & 81.00 & 82.00 & 92.00 & 85.00 & 90.00 \\
10 & K & 0.620 & 0.64 & 0.840 & 0.7 & 0.8 \\
11 & RMSE & 0.378 & 0.3735 & 0.396 & 0.364 & 0.2769 \\
\hline
\end{tabular}

In respect to the validation dataset, RAB-ADT had the highest values of PPV (81.82\%), followed by B-ADT (77.27\%), MBAB-ADT (72.73\%), ADT, and D-ADT (63.64\%), respectively. In the case of NPV, ADT had the highest value (90.91\%), followed by MBAB-ADT (86.36\%), B-ADT, D-ADT $(81.82 \%)$, and RAB-ADT (72.73\%), respectively. SST for the ADT model was $87.50 \%$ which is the highest, followed by MBAB-ADT ( $84.21 \%)$, B-ADT $(80.95 \%)$, D-ADT $(77.78 \%)$ and RAB-ADT $(75 \%)$, respectively. In the case of ACC and kappa values, the values of MBAB-ADT models were better with ACC value: $79.55 \%$ and kappa value: 0.591, compared to other models. The highest SPF was obtained for RAB-ADT model $(80 \%)$, whereas D-ADT had the highest RMSE value 0.463 in comparison to other models (Table 2 and Figure 6). 

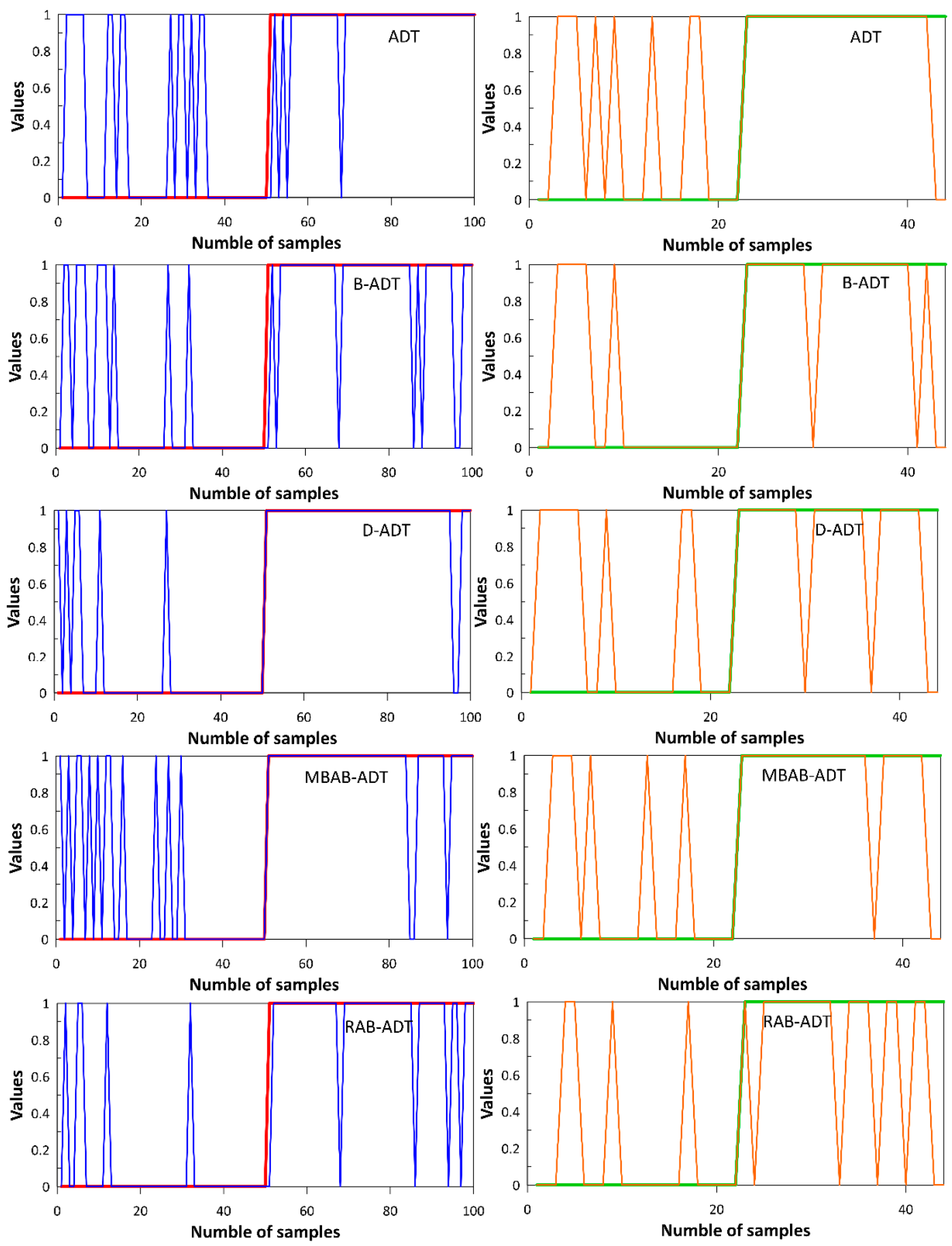

- Actual values of training datasets Predicted values of training datasets

Actual values of validation datasets

Predicted values of validation datasets

Figure 6. Actual and predicted values of models. 
Table 2. Validation of the models using validation dataset.

\begin{tabular}{ccccccc}
\hline No & Criteria & ADT & B-ADT & D-ADT & MBAB-ADT & RAB-ADT \\
\hline 1 & TP & 14 & 17 & 14 & 16 & 18 \\
2 & TN & 20 & 18 & 18 & 19 & 16 \\
3 & FP & 8 & 5 & 8 & 6 & 4 \\
4 & FN & 2 & 4 & 4 & 3 & 6 \\
5 & PPV (\%) & 63.64 & 77.27 & 63.64 & 72.73 & 81.82 \\
6 & NPV (\%) & 90.91 & 81.82 & 81.82 & 86.36 & 72.73 \\
7 & SST (\%) & 87.50 & 80.95 & 77.78 & 84.21 & 75.00 \\
8 & SPF (\%) & 71.43 & 78.26 & 69.23 & 76.00 & 80.00 \\
9 & ACC (\%) & 77.27 & 79.55 & 72.73 & 79.55 & 77.27 \\
10 & K & 0.546 & 0.591 & 0.455 & 0.591 & 0.5455 \\
11 & RMSE & 0.457 & 0.431 & 0.463 & 0.429 & 0.4288 \\
\hline
\end{tabular}

ROC method was used to determine the predictive capability of the models. For training data, comparison of the AUC values indicated that the RAB-ADT model has the highest degree of good fitness (AUC $=0.979)$, followed by D-ADT $($ AUC $=0.962)$, B-ADT $($ AUC $=0.933)$, ADT $($ AUC $=0.895)$ and MBAB-ADT $($ AUC $=0.884)$, respectively. Results based on the validation data show that the B-ADT model with AUC value 0.856 had the highest predictive ability, followed by the MBAB-ADT model with AUC value of 0.812 , the D-ADT with AUC value of 0.808 , and the RAB-ADT with AUC value of 0.799 and ADT with AUC values of 0.763 . All models showed good capability of prediction according to ROC analysis, but performance of the RAB-ADT model was the best for the training data, whereas B-ADT model was the best in the validation of data (Figure 7).

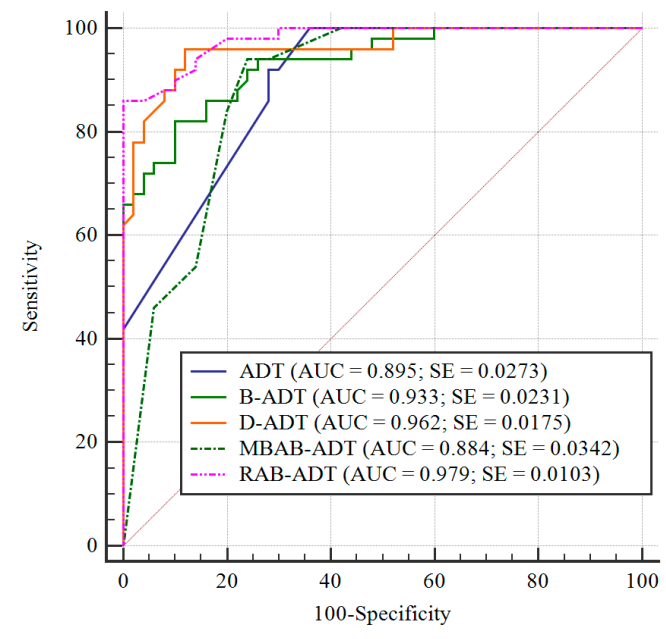

(a)

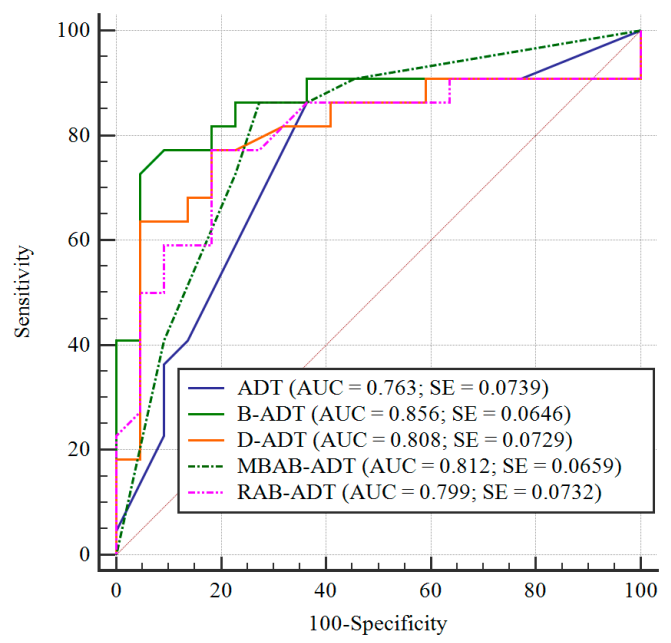

(b)

Figure 7. Analysis of ROC curve of the models: (a) Training dataset, and (b) validation dataset.

Validation results show that performance of all the five models was good in landslide prediction. However, the B-ADT model has the best accuracy and predictive ability compared with other models. Analysis of the results of the models also confirmed that bagging is a useful tool for increasing model prediction accuracy by using an ensemble learning classifier [92]. The ADT model describes a transparent model structure with easier classification rules [37]. In this case, Bagging improved the stability of the ADT model. In addition, the generalization error of the basic classifier is shifted in the bagging model in the direction of the generalization error that is computed on smaller sets of training data. This is one of the benefits of bagging [5,92]. 


\subsection{Generation and Evaluation of Landslide Susceptibility Maps}

Based on the results of the models, landslide susceptibility maps were constructed of Da Lat City, Vietnam using ADT, B-ADT, D-ADT, MBAB-ADT, and RAB-ADT models for better land use planning and decision making for infrastructure development in this area. Landslide susceptibility maps were divided into five classes: Very low, low, moderate, high, very high (Figure 8). Maps generated by the ADT model show that the areas of these susceptibility classes were $21.23 \%, 5.975 \%, 15.26 \%, 36.89 \%$ and $20.65 \%$ for very low, low, moderate, high, very high, respectively. In the case of the B-ADT model, class areas were $17.58 \%, 13.73 \%, 23.4 \%, 24.68 \%, 20.61 \%$ for very low, low, moderate, high, very high, respectively, and for the D-ADT model, the area percentages were $19.67 \%, 11.26 \%, 24.71 \%, 27.93 \%$ and $16.42 \%$, for very low, low, moderate, high, very high, respectively. Whereas, for the MBAB-ADT model, the percentage of class pixels were $27.82 \%, 14.82 \%, 10.97 \%, 24.91 \%$ and $21.47 \%$, for very low, low, moderate, high, very high, respectively, and for the RAB-ADT model, these were $27.06 \%, 19.51 \%$, $15.62 \%, 16 \%, 21.8 \%$. FR analysis on landslide susceptibility maps shows that the map produced by the B-ADT model is the most reliable map compared with those produced by the other models. FR value of the B-ADT model for high and very high susceptibility classes was the highest compared with others (Figure 9). 
(a)

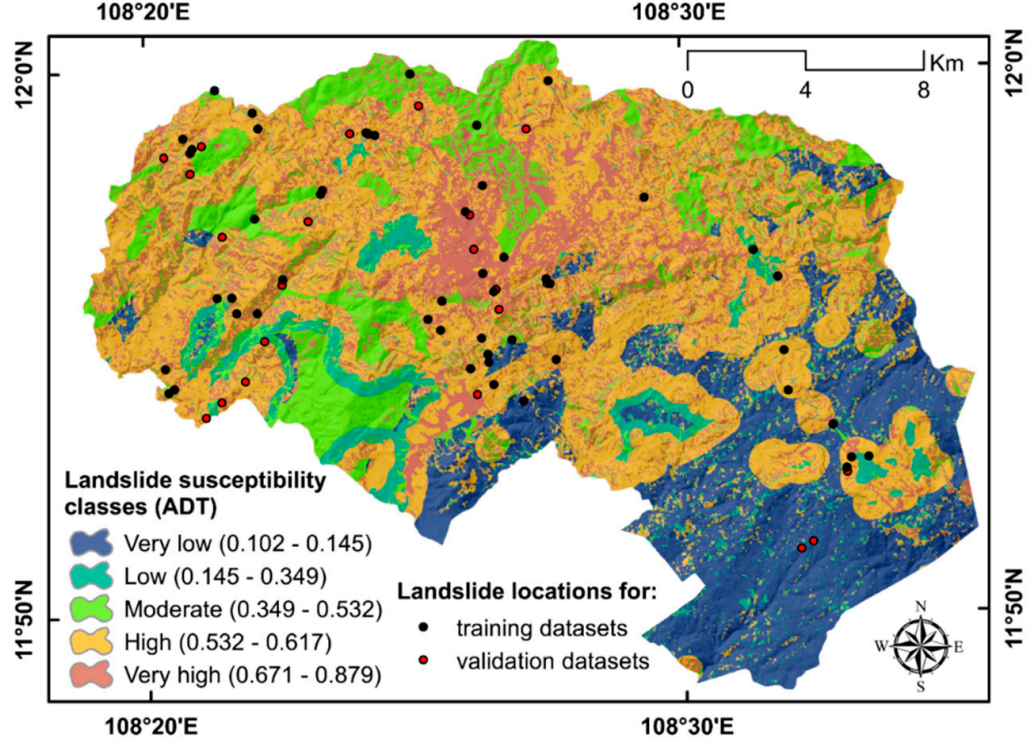

(b) $\stackrel{\circ}{\doteqdot}$

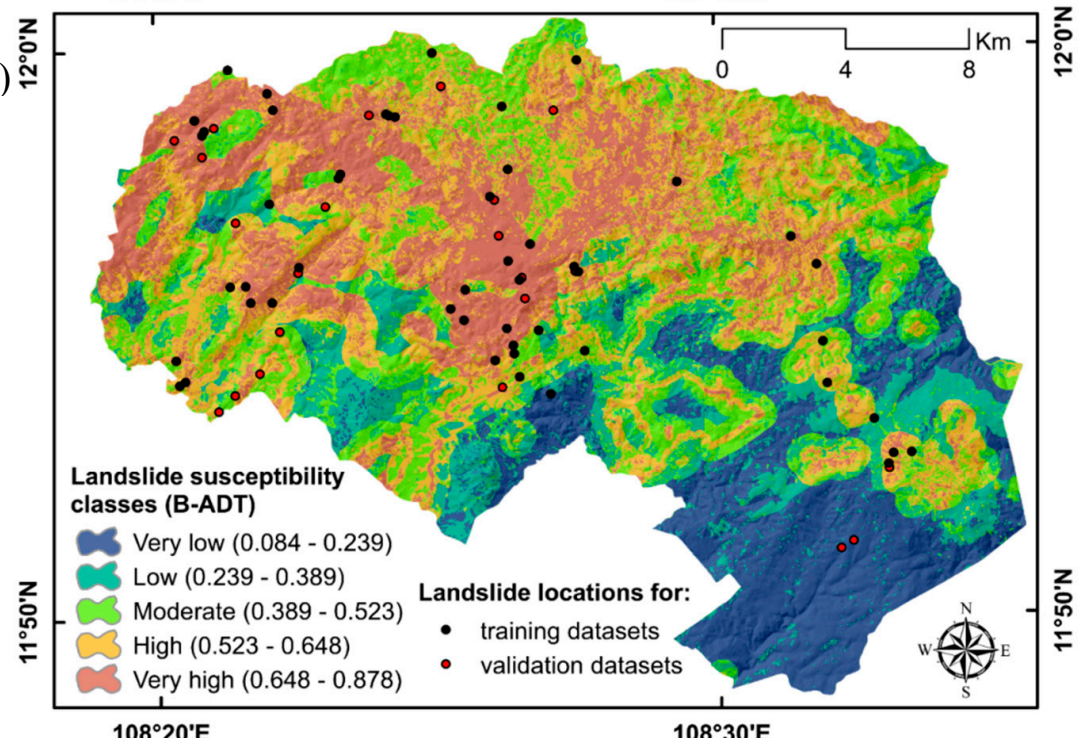

$108^{\circ} 20^{\prime} \mathrm{E}$

$108^{\circ} 30^{\prime} \mathrm{E}$

(c)

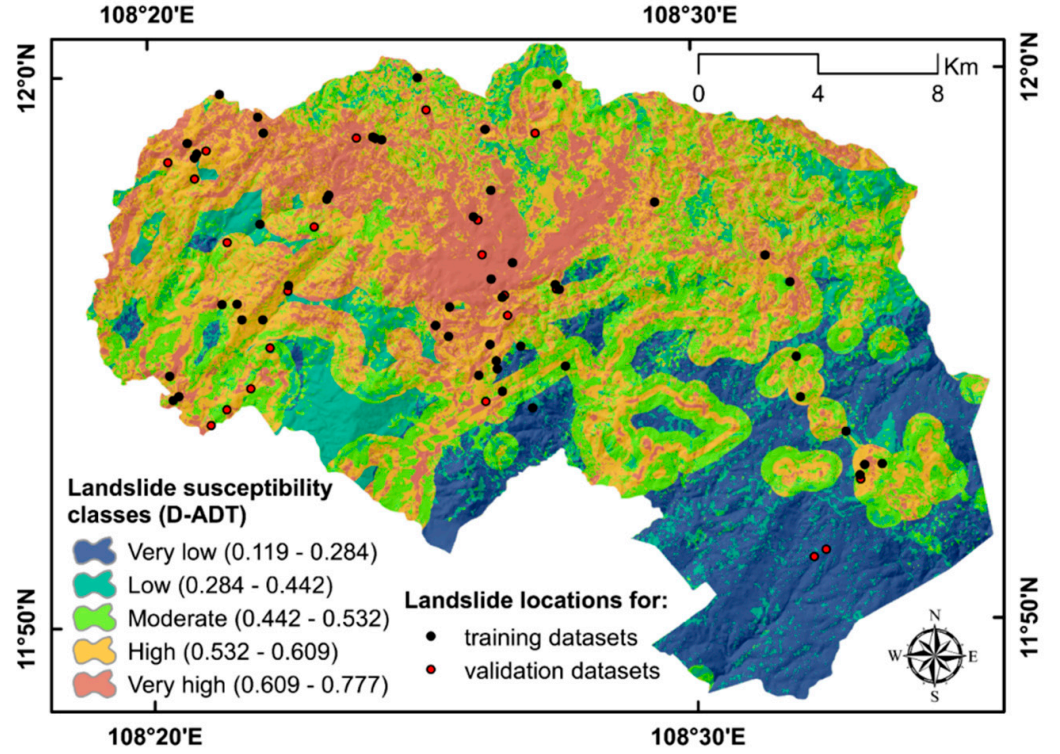

Figure 8. Cont. 

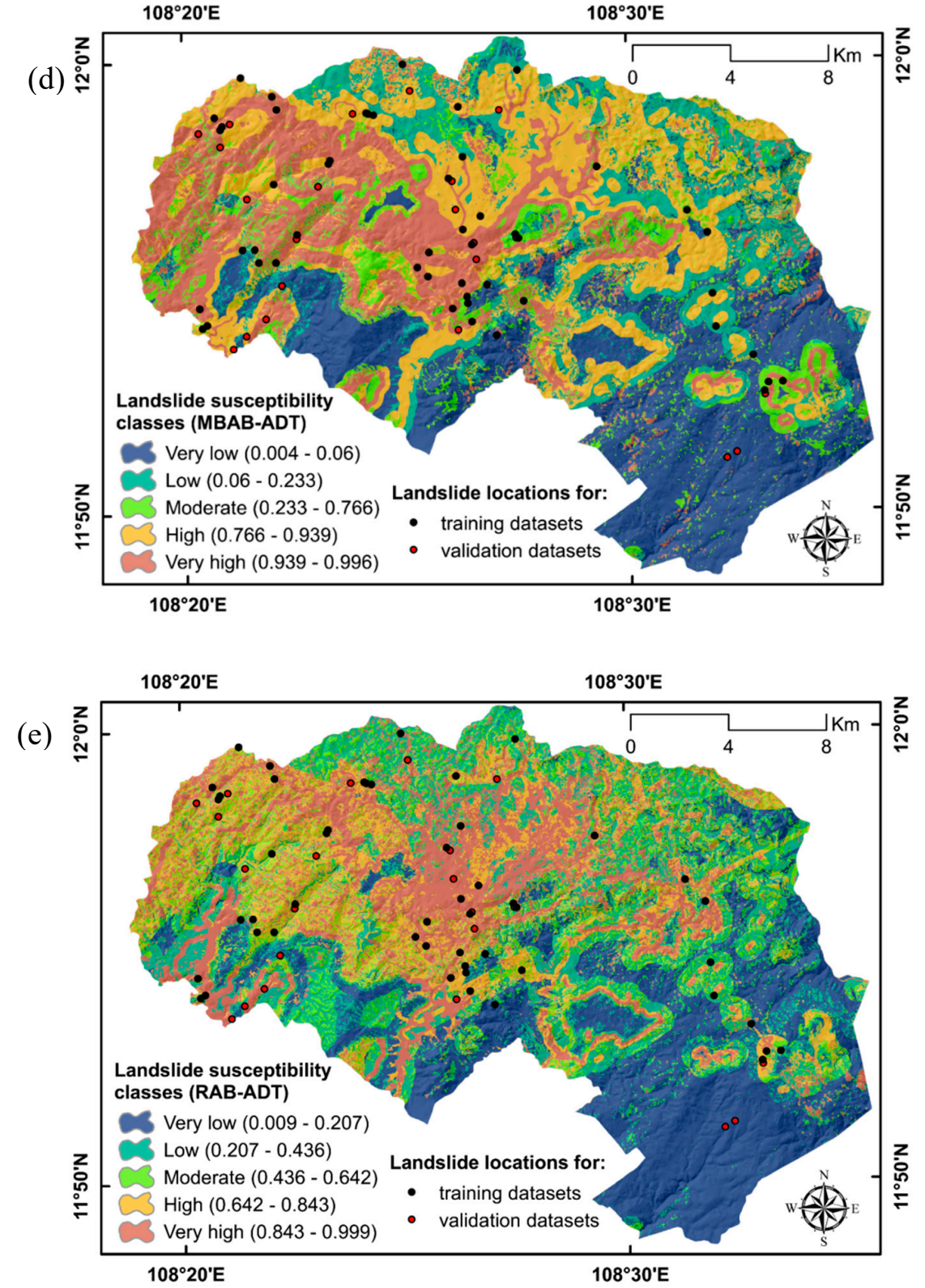

Figure 8. Landslide susceptibility maps of the models: (a) ADT, (b) B-ADT, (c) D-ADT, (d) MBAB-ADT, and (e) RAB-ADT. 

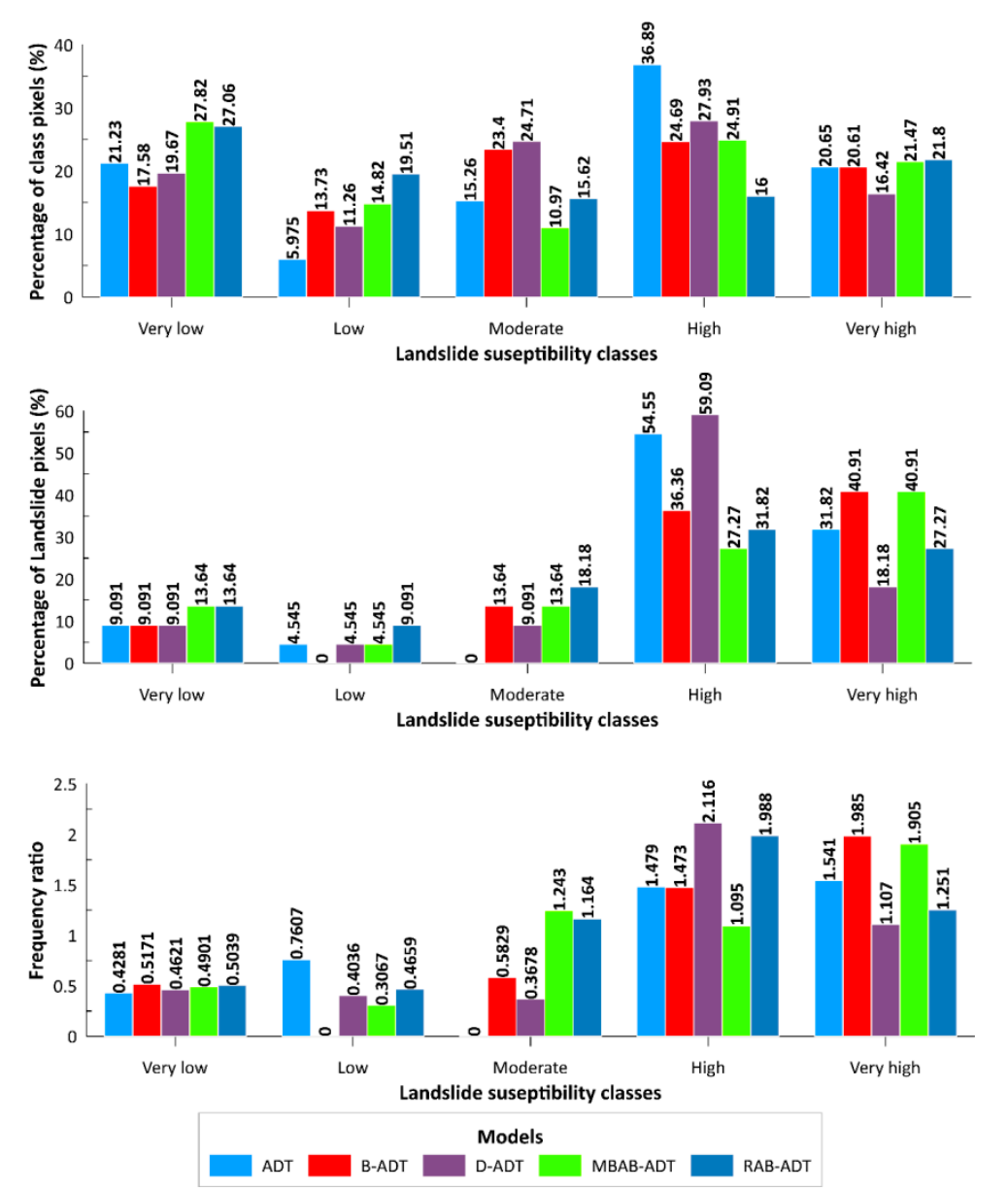

Figure 9. FR analysis of landslide susceptibility maps.

\section{Conclusions}

Selection of a susceptibility model with a strong susceptibility prediction capacity is important. Currently, research to develop suitable, accurate landslide models is still in progress. In this study, new GIS based hybrid computational intelligence models, namely B-ADT, D-ADT, MBAB-ADT, and RAB-ADT, which are a combination of ADT method with various ensemble techniques, namely bagging, dagging, MultiBoostAB, and RealAdaBoost, were proposed and applied in landslide susceptibility mapping at Da Lat City in Lam Dong Province, Vietnam. Various statistical validation criteria such as PPV, NPV, SST, SPE, ACC, RMSE, kappa, and AUC were used to validate the performance of the models on both training and testing datasets generated using 72 past landslide events and 11 landslide conditioning factors.

The results show that all developed and applied models performed well for landslide susceptibility mapping, but the B-ADT model is the best compared with other models (D-ADT, MBAB-ADT, RAB-ADT, and ADT). The results also confirmed that ensemble techniques like bagging, dagging, MultiBoostAB, and RealAdaBoost are effective in the improvement of the performance of single ADT classifiers, but bagging is a better ensemble technique compared with others. It was noticed that the ensemble technique is useful to aggregate and improve the predictive capability of the single classifier, but it cannot reduce the uncertainties from using various models.

Landslide susceptibility maps produced by the models, especially the B-ADT model in this study, would be helpful to decision makers in better risk management for land use planning and infrastructure development, not only in Vietnam, but also in other landslide prone areas in the world. However, performances of these models need to be evaluated in other areas having different geo-environmental 
conditions. Rainfall—considered as one of the triggering factors of landslides—was not considered separately in this study.

Author Contributions: Conceptualization, V.-T.N., A.-A.N., L.S.H. and B.T.P.; methodology, V.P.T., A.-A.N. and B.T.P.; validation, A.-A.N., I.P., A.A. and B.T.P.; formal analysis, V.-T.N., A.-A.N. and B.T.P.; investigation, V.-T.N., V.-T.N., T.H.T., N.A.H. and B.T.P.; data curation, T.H.T., N.A.H., V.P.T. and V.L.N.; writing-original draft preparation, H.D.N., V.-T.N., T.H.T., L.S.H., M.M.A., A.A., N.A.H., V.P.T. and V.L.N.; writing—review and editing, A.-A.N., I.P., L.S.H., A.A. and B.T.P.; visualization, V.P.T. and H.D.N.; supervision, A.-A.N., I.P., A.A. and B.T.P.; project administration, A.-A.N. and B.T.P.; funding acquisition, A.-A.N. and B.T.P.

Funding: This research was funded by the project's code TN18/T13, which belongs to the Central Highland Program No.3, Vietnam Academy of Science and Technology, Vietnam.

Acknowledgments: This research was fully supported by the project's code TN18/T13, which belongs to the Central Highland Program No.3, Vietnam Academy of Science and Technology, Vietnam. We also thank to Institute of Geological Sciences, Vietnam Academy of Science and Technology for supporting this research

Conflicts of Interest: The authors declare no conflict of interest.

\section{References}

1. Yesilnacar, E.; Topal, T. Landslide susceptibility mapping: A comparison of logistic regression and neural networks methods in a medium scale study, Hendek region (Turkey). Eng. Geol. 2005, 79, 251-266. [CrossRef]

2. Nguyen Thi To, N.; Liu, C.-C. A New Approach Using AHP to Generate Landslide Susceptibility Maps in the Chen-Yu-Lan Watershed, Taiwan. Sensors 2019, 19, 505. [CrossRef] [PubMed]

3. Guzzetti, F.; Carrara, A.; Cardinali, M.; Reichenbach, P. Landslide hazard evaluation: A review of current techniques and their application in a multi-scale study, Central Italy. Geomorphology 1999, 31, 181-216. [CrossRef]

4. Dilley, M.; Chen, R.S.; Deichmann, U.; Lerner-Lam, A.; Arnold, M.; Agwe, J.; Buys, P.; Kjekstad, O.; Lyon, B.; Yetman, G. Natural disaster hotspots: A global risk analysis. World Bank Disaster Risk Manag. Ser. 2005, 5, 1-132. [CrossRef]

5. Pham, B.T.; Prakash, I. A novel hybrid model of bagging-based naïve bayes trees for landslide susceptibility assessment. Bull. Eng. Geol. Environ. 2019, 78, 1911-1925. [CrossRef]

6. Westen, C.J.; Alkema, D.; Jetten, V.G.; Hazarika, M. Geo-Information Technology for Hazard Risk Assessment (GHITRA) Project; e-Asia and Knowledge Partnership Fund: Seoul, Korea, 2016.

7. Lee, S.; Dan, N. Probabilistic landslide susceptibility mapping in the Lai Chau province of Vietnam: Focus on the relationship between tectonic fractures and landslides. Environ. Geol. 2005, 48, 778-787. [CrossRef]

8. Phong, T.V.; Phan, T.T.; Prakash, I.; Singh, S.K.; Shirzadi, A.; Chapi, K.; Ly, H.-B.; Ho, L.S.; Quoc, N.K.; Pham, B.T. Landslide susceptibility modeling using different artificial intelligence methods: A case study at Muong Lay district, Vietnam. Geocarto Int. 2019, 1-24. [CrossRef]

9. Tien Bui, D.; Hoang, N.-D.; Samui, P. Spatial pattern analysis and prediction of forest fire using new machine learning approach of Multivariate Adaptive Regression Splines and Differential Flower Pollination optimization: A case study at Lao Cai province (Viet Nam). J. Environ. Manag. 2019, 237, 476-487. [CrossRef]

10. Pourghasemi, H.R.; Pradhan, B.; Gokceoglu, C. Application of fuzzy logic and analytical hierarchy process (AHP) to landslide susceptibility mapping at Haraz watershed, Iran. Nat. Hazards 2012, 63, 965-996. [CrossRef]

11. Kayastha, P.; Dhital, M.R.; De Smedt, F. Application of the analytical hierarchy process (AHP) for landslide susceptibility mapping: A case study from the Tinau watershed, west Nepal. Comput. Geosci. 2013, 52, 398-408. [CrossRef]

12. Lee, S.; Pradhan, B. Landslide hazard mapping at Selangor, Malaysia using frequency ratio and logistic regression models. Landslides 2007, 4, 33-41. [CrossRef]

13. Pradhan, B.; Lee, S. Landslide susceptibility assessment and factor effect analysis: Backpropagation artificial neural networks and their comparison with frequency ratio and bivariate logistic regression modelling. Environ. Model. Softw. 2010, 25, 747-759. [CrossRef]

14. Althuwaynee, O.F.; Pradhan, B.; Lee, S. Application of an evidential belief function model in landslide susceptibility mapping. Comput. Geosci. 2012, 44, 120-135. [CrossRef] 
15. Pradhan, A.M.S.; Kim, Y.-T. Spatial data analysis and application of evidential belief functions to shallow landslide susceptibility mapping at Mt. Umyeon, Seoul, Korea. Bull. Eng. Geol. Environ. 2017, 76, 1263-1279. [CrossRef]

16. Dahal, R.K.; Hasegawa, S.; Nonomura, A.; Yamanaka, M.; Masuda, T.; Nishino, K. GIS-based weights-of-evidence modelling of rainfall-induced landslides in small catchments for landslide susceptibility mapping. Environ. Geol. 2008, 54, 311-324. [CrossRef]

17. Neuhäuser, B.; Terhorst, B. Landslide susceptibility assessment using "weights-of-evidence" applied to a study area at the Jurassic escarpment (SW-Germany). Geomorphology 2007, 86, 12-24. [CrossRef]

18. Arabameri, A.; Pradhan, B.; Rezaei, K.; Lee, S.; Sohrabi, M.J. An Ensemble Model for Landslide Susceptibility Mapping in a Forested Area. Geocarto Int. 2019, 1-25. [CrossRef]

19. Pham, B.T.; Bui, D.T.; Pourghasemi, H.R.; Indra, P.; Dholakia, M. Landslide susceptibility assesssment in the Uttarakhand area (India) using GIS: A comparison study of prediction capability of naïve bayes, multilayer perceptron neural networks, and functional trees methods. Theor. Appl. Climatol. 2017, 128, 255-273. [CrossRef]

20. Tsangaratos, P.; Ilia, I. Comparison of a logistic regression and Naïve Bayes classifier in landslide susceptibility assessments: The influence of models complexity and training dataset size. Catena 2016, 145, 164-179. [CrossRef]

21. Bui, D.T.; Tuan, T.A.; Klempe, H.; Pradhan, B.; Revhaug, I. Spatial prediction models for shallow landslide hazards: A comparative assessment of the efficacy of support vector machines, artificial neural networks, kernel logistic regression, and logistic model tree. Landslides 2016, 13, 361-378.

22. Chen, W.; Xie, X.; Wang, J.; Pradhan, B.; Hong, H.; Bui, D.T.; Duan, Z.; Ma, J. A comparative study of logistic model tree, random forest, and classification and regression tree models for spatial prediction of landslide susceptibility. Catena 2017, 151, 147-160. [CrossRef]

23. Ballabio, C.; Sterlacchini, S. Support vector machines for landslide susceptibility mapping: The Staffora River Basin case study, Italy. Math. Geosci. 2012, 44, 47-70. [CrossRef]

24. Yao, X.; Tham, L.; Dai, F. Landslide susceptibility mapping based on support vector machine: A case study on natural slopes of Hong Kong, China. Geomorphology 2008, 101, 572-582. [CrossRef]

25. Pradhan, B.; Sezer, E.A.; Gokceoglu, C.; Buchroithner, M.F. Landslide susceptibility mapping by neuro-fuzzy approach in a landslide-prone area (Cameron Highlands, Malaysia). IEEE Trans. Geosci. Remote Sens. 2010, 48, 4164-4177. [CrossRef]

26. Oh, H.-J.; Pradhan, B. Application of a neuro-fuzzy model to landslide-susceptibility mapping for shallow landslides in a tropical hilly area. Comput. Geosci. 2011, 37, 1264-1276. [CrossRef]

27. Yeon, Y.-K.; Han, J.-G.; Ryu, K.H. Landslide susceptibility mapping in Injae, Korea, using a decision tree. Eng. Geol. 2010, 116, 274-283. [CrossRef]

28. Kutlug Sahin, E.; Colkesen, I. Performance analysis of advanced decision tree-based ensemble learning algorithms for landslide susceptibility mapping. Geocarto Int. 2019, 1-23. [CrossRef]

29. Can, A.; Dagdelenler, G.; Ercanoglu, M.; Sonmez, H. Landslide susceptibility mapping at Ovacık-Karabük (Turkey) using different artificial neural network models: Comparison of training algorithms. Bull. Eng. Geol. Environ. 2019, 78, 89-102. [CrossRef]

30. Ermini, L.; Catani, F.; Casagli, N. Artificial neural networks applied to landslide susceptibility assessment. Geomorphology 2005, 66, 327-343. [CrossRef]

31. Ayalew, L.; Yamagishi, H. The application of GIS-based logistic regression for landslide susceptibility mapping in the Kakuda-Yahiko Mountains, Central Japan. Geomorphology 2005, 65, 15-31. [CrossRef]

32. Duman, T.Y.; Can, T.; Gokceoglu, C.; Nefeslioglu, H.A.; Sonmez, H. Application of logistic regression for landslide susceptibility zoning of Cekmece Area, Istanbul, Turkey. Environ. Geol. 2006, 51, 241-256. [CrossRef]

33. He, Q.; Shahabi, H.; Shirzadi, A.; Li, S.; Chen, W.; Wang, N.; Chai, H.; Bian, H.; Ma, J.; Chen, Y.; et al. Landslide spatial modelling using novel bivariate statistical based Naïve Bayes, RBF Classifier, and RBF Network machine learning algorithms. Sci. Total. Environ. 2019, 663, 1-15. [CrossRef] [PubMed]

34. Bui, D.T.; Hoang, N.-D.; Nguyen, H.; Tran, X.-L. Spatial prediction of shallow landslide using Bat algorithm optimized machine learning approach: A case study in Lang Son Province, Vietnam. Adv. Eng. Inform. 2019, $42,100978$. 
35. Chen, W.; Shirzadi, A.; Shahabi, H.; Ahmad, B.B.; Zhang, S.; Hong, H.; Zhang, N. A novel hybrid artificial intelligence approach based on the rotation forest ensemble and naïve Bayes tree classifiers for a landslide susceptibility assessment in Langao County, China. Geomat. Nat. Hazards Risk 2017, 8, 1955-1977. [CrossRef]

36. Chen, W.; Xie, X.; Peng, J.; Wang, J.; Duan, Z.; Hong, H. GIS-based landslide susceptibility modelling: A comparative assessment of kernel logistic regression, Naïve-Bayes tree, and alternating decision tree models. Geomat. Nat. Hazards Risk 2017, 8, 950-973. [CrossRef]

37. Hong, H.; Pradhan, B.; Xu, C.; Tien Bui, D. Spatial prediction of landslide hazard at the Yihuang area (China) using two-class kernel logistic regression, alternating decision tree and support vector machines. CATENA 2015, 133, 266-281. [CrossRef]

38. Freund, Y.; Mason, L. The alternating decision tree learning algorithm. ICML 1999, 99, 124-133.

39. Khosravi, K.; Pham, B.T.; Chapi, K.; Shirzadi, A.; Shahabi, H.; Revhaug, I.; Prakash, I.; Bui, D.T. A comparative assessment of decision trees algorithms for flash flood susceptibility modeling at Haraz watershed, northern Iran. Sci. Total Environ. 2018, 627, 744-755. [CrossRef]

40. Galar, M.; Fernandez, A.; Barrenechea, E.; Bustince, H.; Herrera, F. A review on ensembles for the class imbalance problem: Bagging-, boosting-, and hybrid-based approaches. IEEE Trans. Syst. ManCybern. Part C Appl. Rev. 2011, 42, 463-484. [CrossRef]

41. He, Q.; Xu, Z.; Li, S.; Li, R.; Zhang, S.; Wang, N.; Pham, B.; Chen, W. Novel Entropy and Rotation Forest-Based Credal Decision Tree Classifier for Landslide Susceptibility Modeling. Entropy 2019, 21, 106. [CrossRef]

42. Tien Bui, D.; Ho, T.; Pradhan, B.; Pham, B.; Nhu, V.-H.; Revhaug, I. GIS-Based Modeling of Rainfall-Induced Landslides Using Data Mining Based Functional Trees Classifier with AdaBoost, Bagging, and MultiBoost Ensemble Frameworks. Environ. Earth Sci. 2016, 75, 1101. [CrossRef]

43. Ly, H.-B.; Monteiro, E.; Le, T.-T.; Le, V.M.; Dal, M.; Regnier, G.; Pham, B.T. Prediction and sensitivity analysis of bubble dissolution time in 3D selective laser sintering using ensemble decision trees. Materials 2019, 12, 1544. [CrossRef] [PubMed]

44. Breiman, L.J. Bagging predictors. Mach. Learn. 1996, 24, 123-140. [CrossRef]

45. Ting, K.; Witten, I. Stacking Bagged and Dagged Models. In Proceedings of the Fourteenth International Conference on Machine Learning ICML '97, Nashville, TN, USA, 8-12 July 1997.

46. Pham, B.T.; Tien Bui, D.; Prakash, I.; Dholakia, M.B. Hybrid integration of Multilayer Perceptron Neural Networks and machine learning ensembles for landslide susceptibility assessment at Himalayan area (India) using GIS. CATENA 2017, 149, 52-63. [CrossRef]

47. Webb, G. MultiBoosting: A Technique for Combining Boosting and Wagging. Mach. Learn. 2000, 40, $159-196$. [CrossRef]

48. Schapire, R.E.; Singer, Y. Improved boosting algorithms using confidence-rated predictions. Mach. Learn. 1999, 37, 297-336. [CrossRef]

49. Freund, Y.; Schapire, R.E. A decision-theoretic generalization of on-line learning and an application to boosting. J. Comput. Syst. Sci. 1997, 55, 119-139. [CrossRef]

50. Pham, B.T.; Bui, D.T.; Pham, H.V.; Le, H.Q.; Prakash, I.; Dholakia, M.B. Landslide hazard assessment using random subspace fuzzy rules based classifier ensemble and probability analysis of rainfall data: A case study at Mu Cang Chai District, Yen Bai Province (Viet Nam). J. Indian Soc. Remote Sens. 2017, 45, 673-683. [CrossRef]

51. Pham, B.T.; Prakash, I.; Singh, S.K.; Shirzadi, A.; Shahabi, H.; Bui, D.T. Landslide susceptibility modeling using Reduced Error Pruning Trees and different ensemble techniques: Hybrid machine learning approaches. Catena 2019, 175, 203-218. [CrossRef]

52. Shirzadi, A.; Soliamani, K.; Habibnejhad, M.; Kavian, A.; Chapi, K.; Shahabi, H.; Chen, W.; Khosravi, K.; Thai Pham, B.; Pradhan, B.J. Novel GIS based machine learning algorithms for shallow landslide susceptibility mapping. Sensors 2018, 18, 3777. [CrossRef]

53. Thai Pham, B.; Shirzadi, A.; Shahabi, H.; Omidvar, E.; Singh, S.K.; Sahana, M.; Talebpour Asl, D.; Bin Ahmad, B.; Kim Quoc, N.; Lee, S.J. Landslide susceptibility assessment by novel hybrid machine learning algorithms. Sustainability 2019, 11, 4386. [CrossRef]

54. Bennett, N.D.; Croke, B.F.; Guariso, G.; Guillaume, J.H.; Hamilton, S.H.; Jakeman, A.J.; Marsili-Libelli, S.; Newham, L.T.; Norton, J.P.; Perrin, C. Characterising performance of environmental models. Environ. Model. Softw. 2013, 40,1-20. [CrossRef] 
55. Janizadeh, S.; Avand, M.; Jaafari, A.; Phong, T.V.; Bayat, M.; Ahmadisharaf, E.; Prakash, I.; Pham, B.T.; Lee, S.J. Prediction Success of Machine Learning Methods for Flash Flood Susceptibility Mapping in the Tafresh Watershed, Iran. Sustainability 2019, 11, 5426. [CrossRef]

56. Pham, B.; Tien Bui, D.; Dholakia, M.; Prakash, I.; Pham, H. A Comparative Study of Least Square Support Vector Machines and Multiclass Alternating Decision Trees for Spatial Prediction of Rainfall-Induced Landslides in a Tropical Cyclones Area. Geotech. Geol. Eng. 2016, 34, 1807-1824. [CrossRef]

57. Asteris, P.G.; Ashrafian, A.; Rezaie-Balf, M. Prediction of the compressive strength of self-compacting concrete using surrogate models. Comput. Concr. 2019, 24, 137-150.

58. Asteris, P.G.; Nozhati, S.; Nikoo, M.; Cavaleri, L.; Nikoo, M. Krill herd algorithm-based neural network in structural seismic reliability evaluation. Mech. Adv. Mater. Struct. 2019, 26, 1146-1153. [CrossRef]

59. Qi, C.; Ly, H.-B.; Chen, Q.; Le, T.-T.; Le, V.M.; Pham, B.T.J.C. Flocculation-dewatering prediction of fine mineral tailings using a hybrid machine learning approach. Chemosphere 2019, 125450. [CrossRef]

60. Asteris, P.G.; Kolovos, K.G. Self-compacting concrete strength prediction using surrogate models. Neural Comput. Appl. 2019, 31, 409-424. [CrossRef]

61. Asteris, P.G.; Nikoo, M. Artificial bee colony-based neural network for the prediction of the fundamental period of infilled frame structures. Neural Comput. Appl. 2019, 1-11. [CrossRef]

62. Chen, H.; Asteris, P.G.; Jahed Armaghani, D.; Gordan, B.; Pham, B.T. Assessing dynamic conditions of the retaining wall: Developing two hybrid intelligent models. Appl. Sci. 2019, 9, 1042. [CrossRef]

63. Le, L.M.; Ly, H.-B.; Pham, B.T.; Le, V.M.; Pham, T.A.; Nguyen, D.-H.; Tran, X.-T.; Le, T.-T. Hybrid Artificial Intelligence Approaches for Predicting Buckling Damage of Steel Columns Under Axial Compression. Materials 2019, 12, 1670. [CrossRef] [PubMed]

64. Ly, H.-B.; Pham, B.T.; Dao, D.V.; Le, V.M.; Le, L.M.; Le, T.-T. Improvement of ANFIS Model for Prediction of Compressive Strength of Manufactured Sand Concrete. Appl. Sci. 2019, 9, 3841. [CrossRef]

65. Armaghani, D.J.; Hatzigeorgiou, G.D.; Karamani, C.; Skentou, A.; Zoumpoulaki, I.; Asteris, P.G. Soft computing-based techniques for concrete beams shear strength. Procedia Struct. Integr. 2019, 17, 924-933. [CrossRef]

66. Cavaleri, L.; Asteris, P.G.; Psyllaki, P.P.; Douvika, M.G.; Skentou, A.D.; Vaxevanidis, N.M. Prediction of surface treatment effects on the tribological performance of tool steels using artificial neural networks. Appl. Sci. 2019, 9, 2788. [CrossRef]

67. Sarir, P.; Chen, J.; Asteris, P.G.; Armaghani, D.J.; Tahir, M. Developing GEP tree-based, neuro-swarm, and whale optimization models for evaluation of bearing capacity of concrete-filled steel tube columns. Eng. Comput. 2019, 1-19. [CrossRef]

68. Pham, B.T.; Nguyen, M.D.; Bui, K.-T.T.; Prakash, I.; Chapi, K.; Bui, D.T.J.C. A novel artificial intelligence approach based on Multi-layer Perceptron Neural Network and Biogeography-based Optimization for predicting coefficient of consolidation of soil. Catena 2019, 173, 302-311. [CrossRef]

69. Pham, B.T.; Bui, D.T.; Prakash, I. Bagging based Support Vector Machines for spatial prediction of landslides. Environ. Earth Sci. 2018, 77, 146. [CrossRef]

70. Nohani, E.; Moharrami, M.; Sharafi, S.; Khosravi, K.; Pradhan, B.; Pham, B.T.; Lee, S.; Melesse, A.M. Landslide susceptibility mapping using different GIS-based bivariate models. Water 2019, 11, 1402. [CrossRef]

71. Chapi, K.; Singh, V.P.; Shirzadi, A.; Shahabi, H.; Bui, D.T.; Pham, B.T.; Khosravi, K. A novel hybrid artificial intelligence approach for flood susceptibility assessment. Environ. Model. Softw. 2017, 95, 229-245. [CrossRef]

72. Pham, B.T.; Bui, D.T.; Prakash, I.; Dholakia, M. Rotation forest fuzzy rule-based classifier ensemble for spatial prediction of landslides using GIS. Nat. Hazards 2016, 83, 97-127. [CrossRef]

73. Khosravi, K.; Sartaj, M.; Tsai, F.T.-C.; Singh, V.P.; Kazakis, N.; Melesse, A.M.; Prakash, I.; Bui, D.T.; Pham, B.T. A comparison study of DRASTIC methods with various objective methods for groundwater vulnerability assessment. Sci. Total Environ. 2018, 642, 1032-1049. [CrossRef] [PubMed]

74. Pham, B.T.; Prakash, I.; Jaafari, A.; Bui, D.T. Spatial prediction of rainfall-induced landslides using aggregating one-dependence estimators classifier. J. Indian Soc. Remote Sens. 2018, 46, 1457-1470. [CrossRef]

75. Jaafari, A.; Zenner, E.K.; Pham, B.T. Wildfire spatial pattern analysis in the Zagros Mountains, Iran: A comparative study of decision tree based classifiers. Ecol. Inform. 2018, 43, 200-211. [CrossRef] 
76. Dou, J.; Yunus, A.P.; Bui, D.T.; Merghadi, A.; Sahana, M.; Zhu, Z.; Chen, C.-W.; Khosravi, K.; Yang, Y.; Pham, B.T. Assessment of advanced random forest and decision tree algorithms for modeling rainfall-induced landslide susceptibility in the Izu-Oshima Volcanic Island, Japan. Sci. Total Environ. 2019, 662, 332-346. [CrossRef]

77. Tien Bui, D.; Hoang, N.-D. A Bayesian framework based on a Gaussian mixture model and radial-basis-function Fisher discriminant analysis (BayGmmKda V1.1) for spatial prediction of floods. Geosci. Model Dev. 2017, 10, 1-19. [CrossRef]

78. Hong, H.; Liu, J.; Zhu, A.-X.; Shahabi, H.; Pham, B.T.; Chen, W.; Pradhan, B.; Bui, D.T. A novel hybrid integration model using support vector machines and random subspace for weather-triggered landslide susceptibility assessment in the Wuning area (China). Environ. Earth Sci. 2017, 76, 652. [CrossRef]

79. Tien Bui, D.; Tuan, T.; Hoang, N.-D.; Thanh, N.; Nguyen, D.; Liem, N.; Pradhan, B. Spatial Prediction of Rainfall-induced Landslides for the Lao Cai area (Vietnam) Using a Novel hybrid Intelligent Approach of Least Squares Support Vector Machines Inference Model and Artificial Bee Colony Optimization. Landslides 2017, 14, 447-458. [CrossRef]

80. Chang, K.-T.; Merghadi, A.; Yunus, A.P.; Pham, B.T.; Dou, J. Evaluating scale effects of topographic variables in landslide susceptibility models using GIS-based machine learning techniques. Sci. Rep. 2019, 9, 1-21. [CrossRef]

81. Ayalew, L.; Yamagishi, H.; Ugawa, N. Landslide susceptibility mapping using GIS-based weighted linear combination, the case in Tsugawa area of Agano River, Niigata Prefecture, Japan. Landslides 2004, 1, 73-81. [CrossRef]

82. Naghibi, S.A.; Ahmadi, K.; Daneshi, A. Application of support vector machine, random forest, and genetic algorithm optimized random forest models in groundwater potential mapping. Water Resour. Manag. 2017, 31, 2761-2775. [CrossRef]

83. Pham, B.T.; Jaafari, A.; Prakash, I.; Singh, S.K.; Quoc, N.K.; Bui, D.T. Hybrid computational intelligence models for groundwater potential mapping. Catena 2019, 182, 104101. [CrossRef]

84. Park, S.; Kim, J. Landslide susceptibility mapping based on random Forest and boosted regression tree models, and a comparison of their performance. Appl. Sci. 2019, 9, 942. [CrossRef]

85. Coelho-Netto, A.L.; Avelar, A.S.; Fernandes, M.C.; Lacerda, W.A. Landslide susceptibility in a mountainous geoecosystem, Tijuca Massif, Rio de Janeiro: The role of morphometric subdivision of the terrain. Geomorphology 2007, 87, 120-131. [CrossRef]

86. Shirzadi, A.; Bui, D.T.; Pham, B.T.; Solaimani, K.; Chapi, K.; Kavian, A.; Shahabi, H.; Revhaug, I. Shallow landslide susceptibility assessment using a novel hybrid intelligence approach. Environ. Earth Sci. 2017, 76, 60. [CrossRef]

87. Arulbalaji, P.; Padmalal, D.; Sreelash, K. GIS and AHP techniques based delineation of groundwater potential zones: A case study from southern Western Ghats, India. Sci. Rep. 2019, 9, 2082. [CrossRef]

88. Xu, C.; Xu, X.; Dai, F.; Saraf, A.K. Comparison of different models for susceptibility mapping of earthquake triggered landslides related with the 2008 Wenchuan earthquake in China. Comput. Geosci. 2012, 46, 317-329. [CrossRef]

89. Nefeslioglu, H.A.; Duman, T.Y.; Durmaz, S. Landslide susceptibility mapping for a part of tectonic Kelkit Valley (Eastern Black Sea region of Turkey). Geomorphology 2008, 94, 401-418. [CrossRef]

90. Kavzoglu, T.; Sahin, E.K.; Colkesen, I. Landslide susceptibility mapping using GIS-based multi-criteria decision analysis, support vector machines, and logistic regression. Landslides 2014, 11, 425-439. [CrossRef]

91. Aditian, A.; Kubota, T.; Shinohara, Y.J.G. Comparison of GIS-based landslide susceptibility models using frequency ratio, logistic regression, and artificial neural network in a tertiary region of Ambon, Indonesia. Geomorphology 2018, 318, 101-111. [CrossRef]

92. Chen, W.; Shahabi, H.; Zhang, S.; Khosravi, K.; Shirzadi, A.; Chapi, K.; Pham, B.; Zhang, T.; Zhang, L.; Chai, $\mathrm{H}$. Landslide susceptibility modeling based on gis and novel bagging-based kernel logistic regression. Appl. Sci. 2018, 8, 2540. [CrossRef]

(C) 2019 by the authors. Licensee MDPI, Basel, Switzerland. This article is an open access article distributed under the terms and conditions of the Creative Commons Attribution (CC BY) license (http://creativecommons.org/licenses/by/4.0/). 